\title{
درجة تطبيق معايير الاعتماد في مدارس التعليم الخاص في الأردن
}

\section{أمل صالح محجوب المحارمة}

طالبة دراسات عُليا- الأردن

Saadbanihani@hotmail.com

هدفت الدراسة التعرف إلى تقدير درجة تطبيق معايير الاعتماد في مدارس التعليم الخاص في الأردن، تم استخدام المنهج الوصفي، تكونت عينة

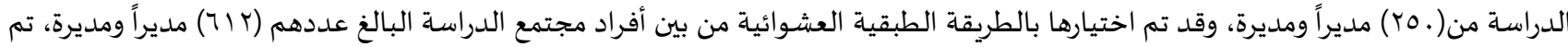

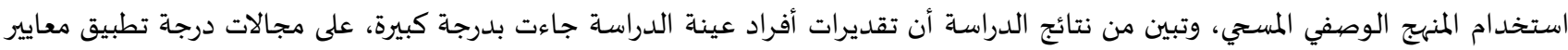

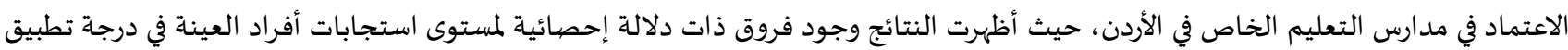

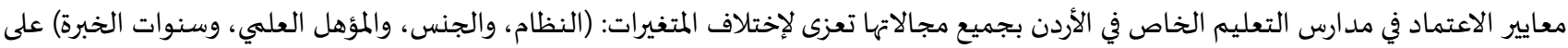

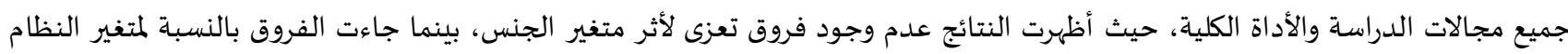

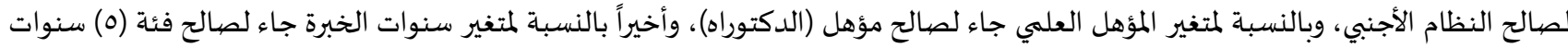

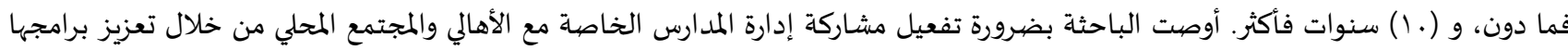

التوعوية والإرشادية.

الكلمات المفتاحية: المدارس الخاصة؛؛ معايير الاعتماد؛ التعليم الخاص. (a) (1)

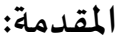

شهدت العقود الثلاثة الماضية العديد من التغيرات في النظم الاقتصادية والاجتماعية والثقافية، والسياسية والتكنولوجية، والإدارية، وخاصية

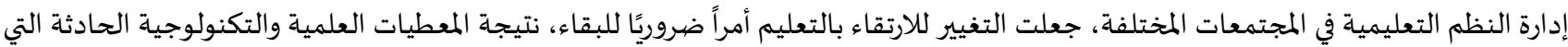
أثرت بشكل كبير على مجال التعليم، مما فرض على النظم التربوية رفع التحدي، وتبني شِعار التعليم والعلم المتميزين تحقيقاً لجودة مخرجاتها من

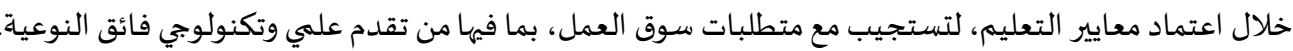
ظهرت تطبيقات معايير الاعتماد في المدارس الخاصة في بدايتها في الولايات المتحدة الأمريكية منذ أوائل القرن العشرين، وقد لاقت استحساناً

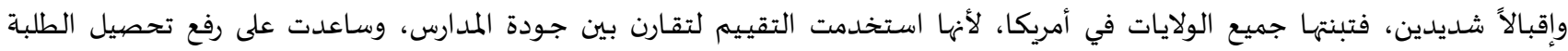

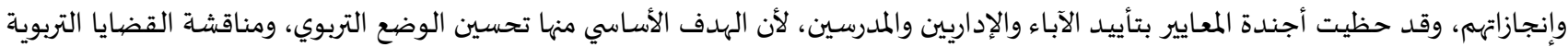

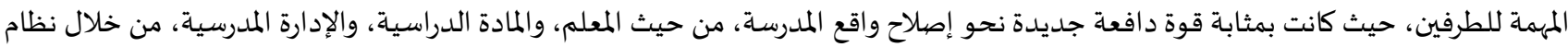

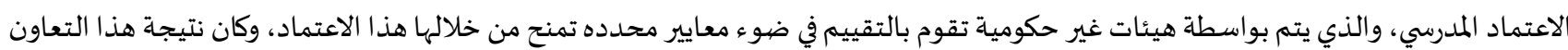

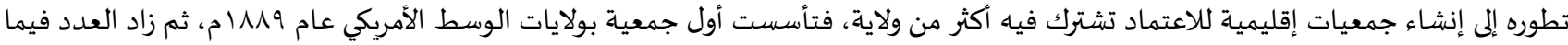

بعد، وكان تركيزها على تقويم واعتماد برامج المؤسسات التعليمية (Gandal \& Vranek, 2001:45).

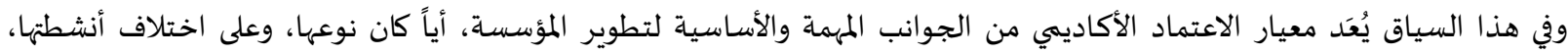

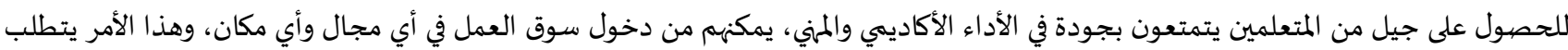
الارتقاء بجودة التعليم، والاستفادة من تجارب الدول التي أثبتت نجاحها في مجال التعليم المباشرة وغير المباشرة، من خلال ترسيخ وتطبيق مفهوم 
والجدير بالذكر أن مجال الجودة والاعتماد في التعليم أصبح من القضايا الرئيسة على المستوى العالمي، وبرزت بذلك هيئات اعتماد دولي

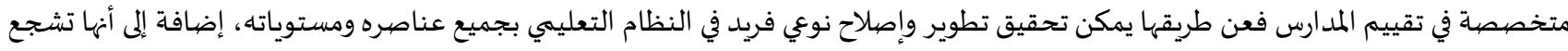

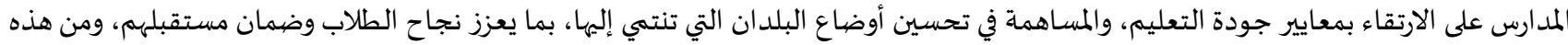

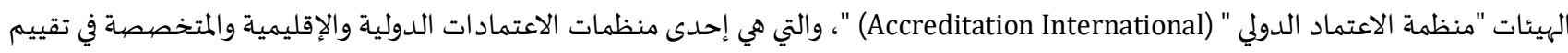

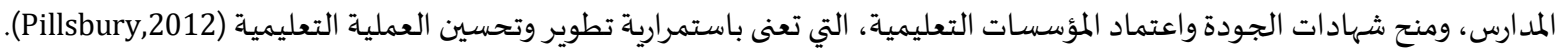

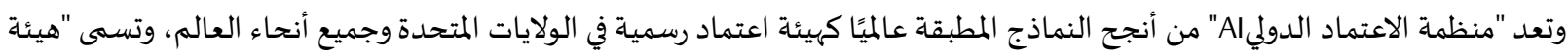

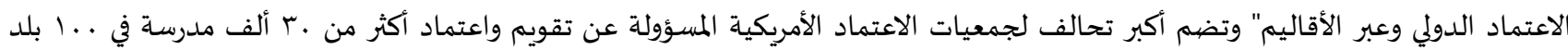

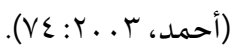

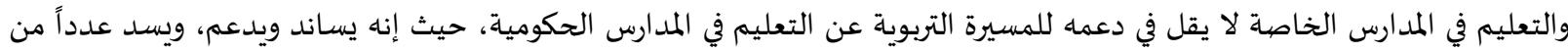

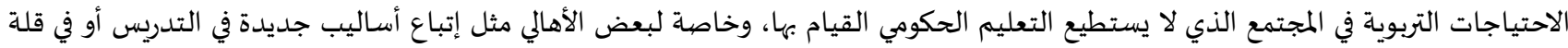

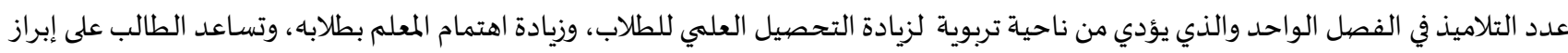

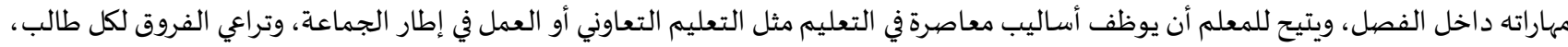

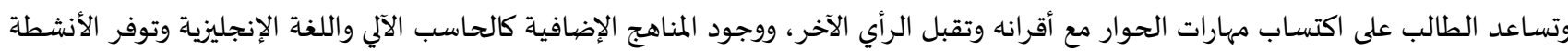

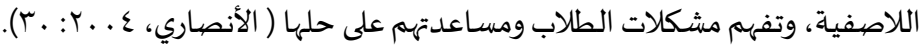

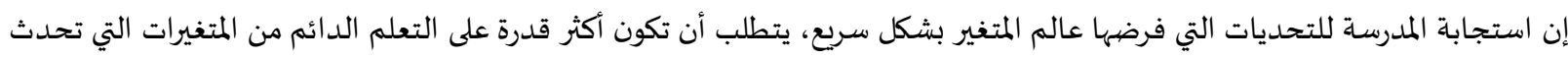

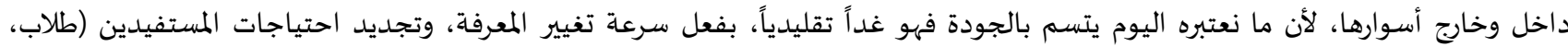

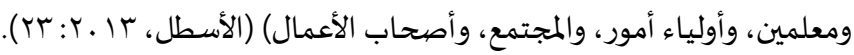

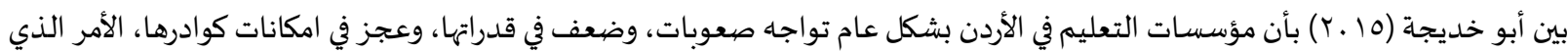

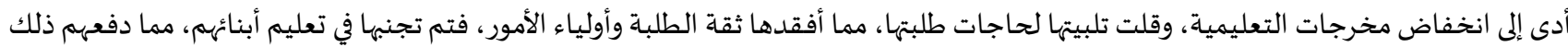

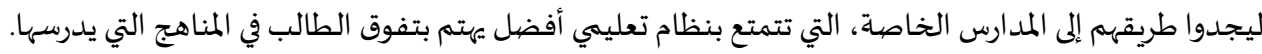

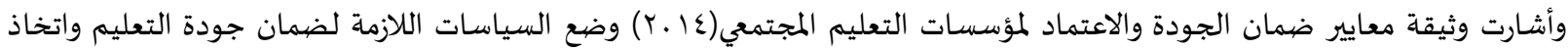

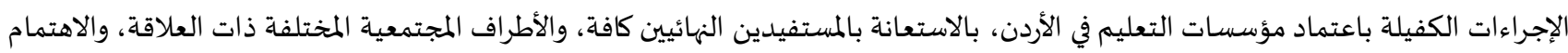

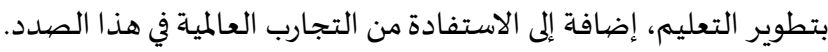

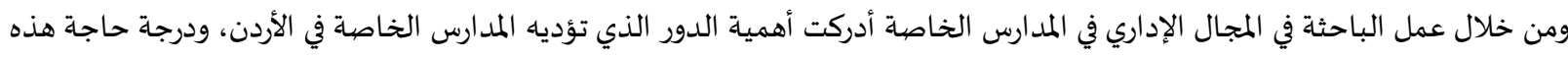

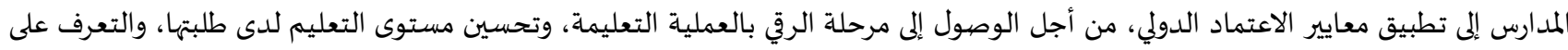

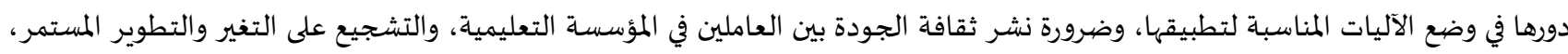

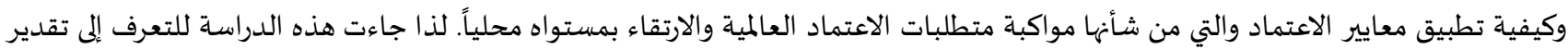
درجة تطبيق معايير الاعتماد في مدارس التعليم الخاص في الأردن.

الدراسات السابقة:

تم في هذا الجزء تناول الدراسات ذات العلاقة بموضوع الدراسة، وقد تم تناولها حسب تسلسلها الزمني من الأقدم إلى الأحدث، حيث قامت

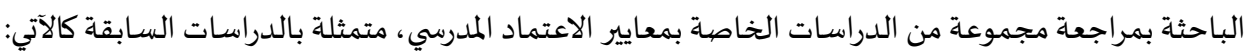

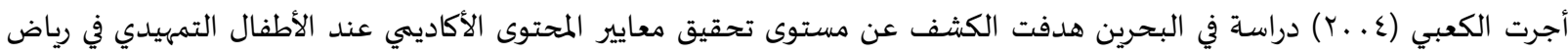

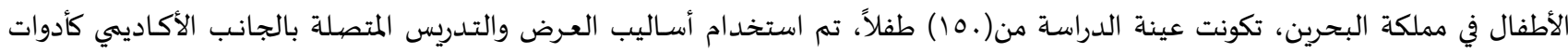

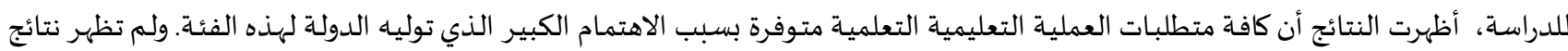

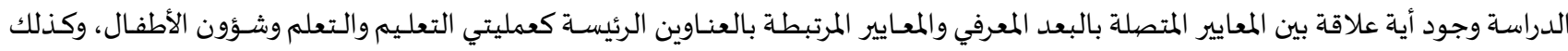
استراتيجيات التدريس واستراتيجيات التقويم، أو معايير قياس كفاية الدعم لمؤسسات رعاية الأطفال.

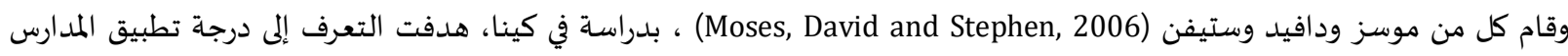

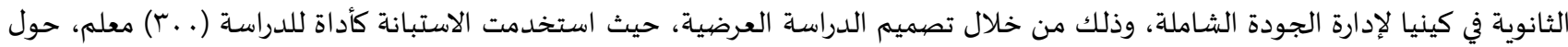

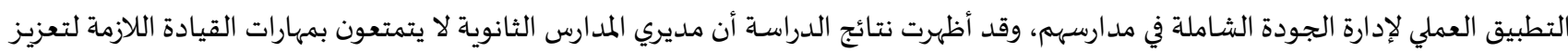

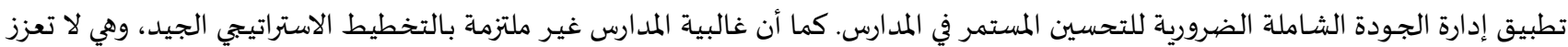
مبادرات تطوير الموارد البشرية. 
وأجرت ذياب والحاج وكيالي (T . . T) دراسة هدفت إلى الكشف عن درجة تطبيق معايير ضمان الجودة من وجهة نظر مديري التعليم

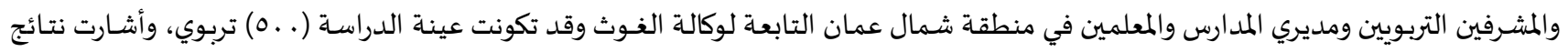

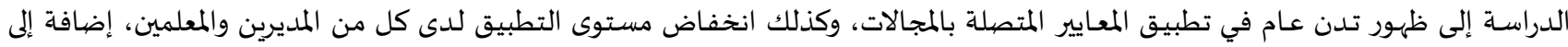

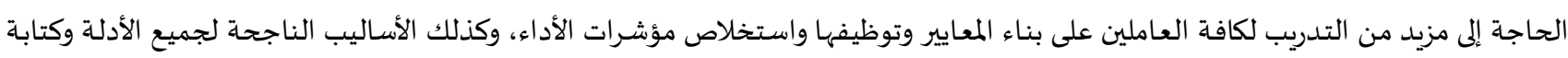
التقارير.

وأجرى ميرهندور(Merhundrew,2010) دراسة هدفت إلى البحث في تصورات جميع مديري المدارس في ولاية متسبي في الولايات المتحدة

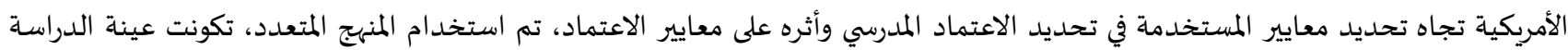

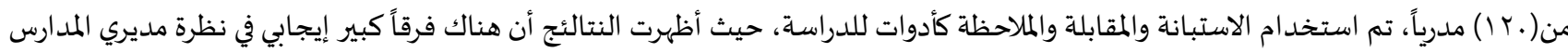

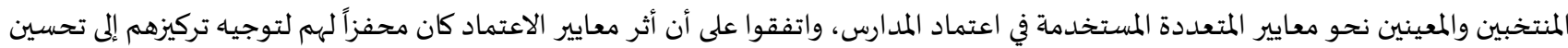
العملية التعليمية من أجل الطلاب.

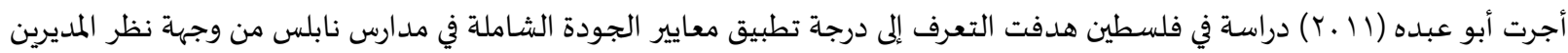

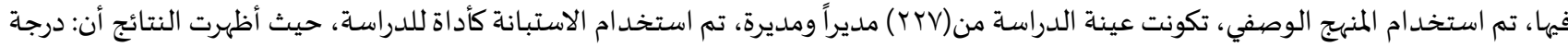

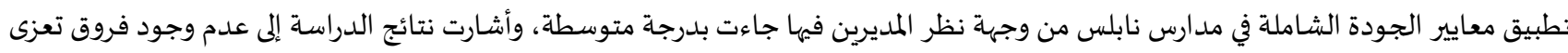

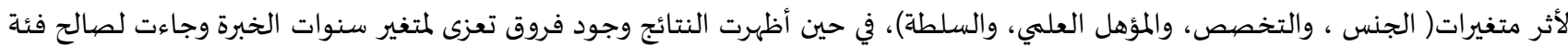

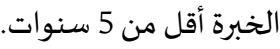

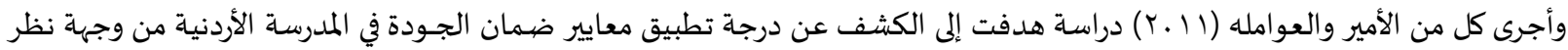

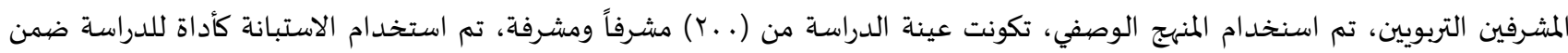

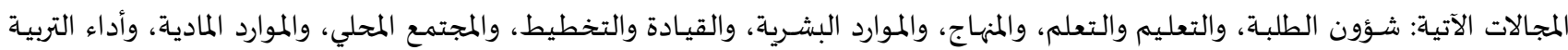

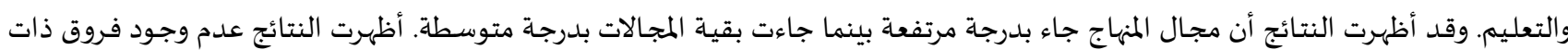

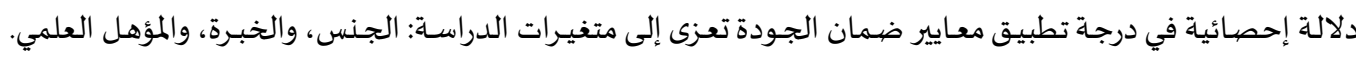

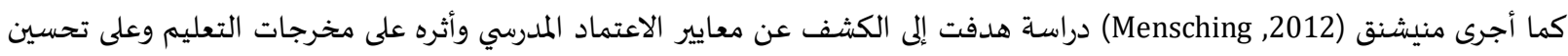

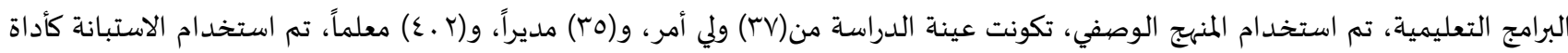

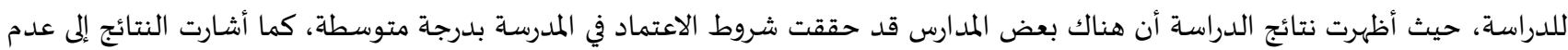
وجود فروق تعزى لمتغير الخبرة.

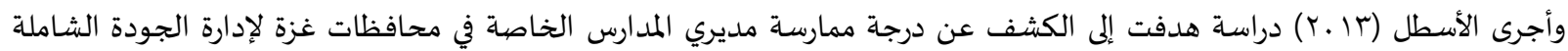

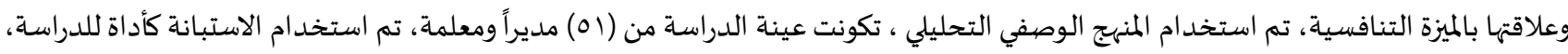

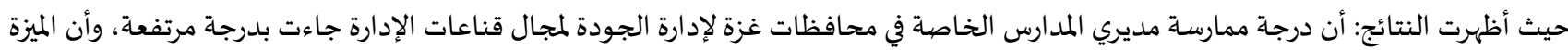

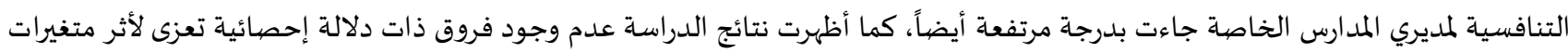

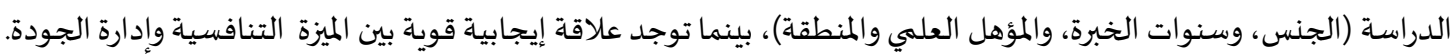

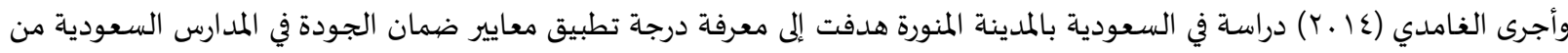

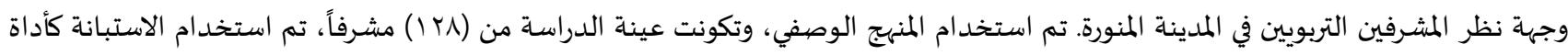

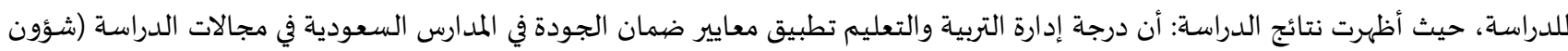

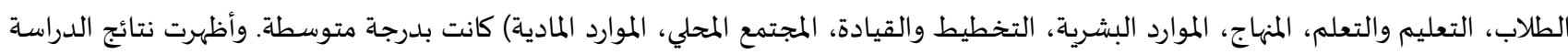
عدم وجود فروق تعزى لأثر متغيري (سنوات الخبرة والمؤهل العلمي).

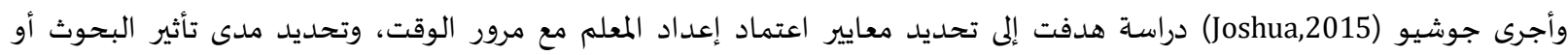

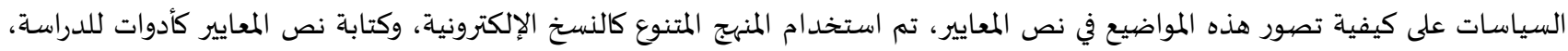

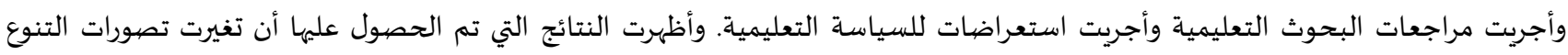

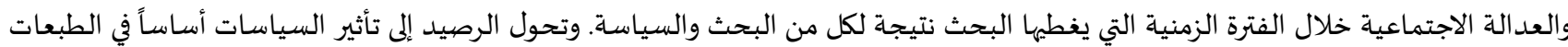
الأحدث من المعايير.

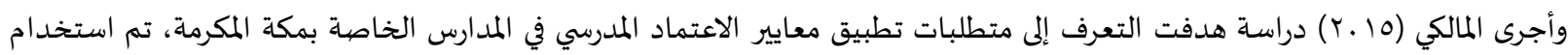

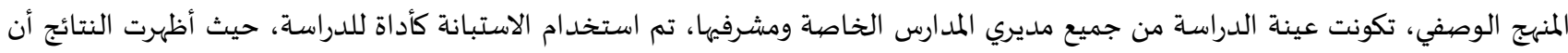

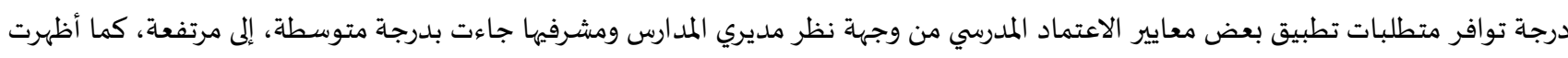


النتائج عدم وجود فروق تعزى لأثر متغيرات ( المسمى الوظيفي، والدورات التدرببية)، بينما توجد فروق تعزى لأثر متغير الخبرة في مجال المباني المدرسية، وجاء لصالح ذوي الخبرة الطويلة.

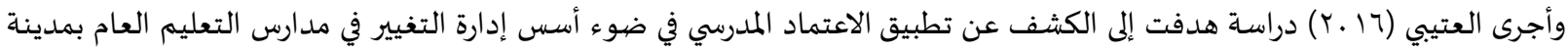

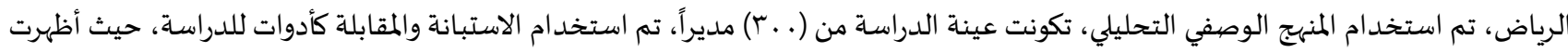

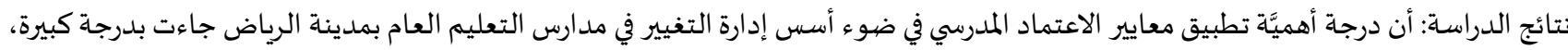

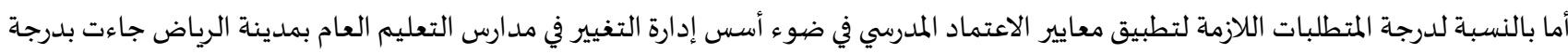
متوسطة.

تم استعراض عدد من الدراسات السـابقة التي تناولت موضوع معايير الاعتماد في المؤسسات التربوية ومعايير الجودة، سعياً إلى إثراء الإطار النظري للدراسة والاستفادة منها في بناء أداة الدراسة اللازمة لجمع البيانات والتعرف إلى الأساليب الإحصائية، وتفسير النتائج التي أسفرت التهرت عنها الدراسة الحالية.

وقد سعت بعض الدراسـات للتعرف إلى درجة تطبيق معايير الاعتماد وما يدور حولها كدراسة (2001. Vranek \& Grand) والتي بحثت في قياس

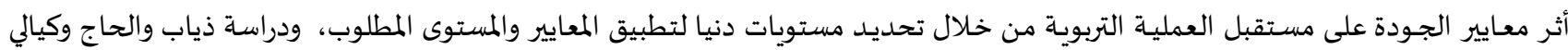

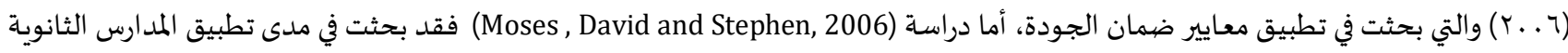

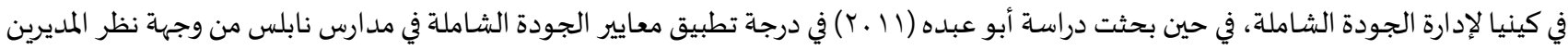

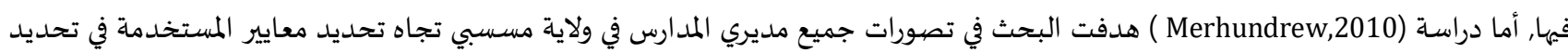

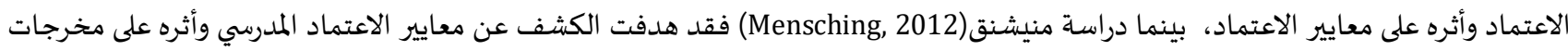

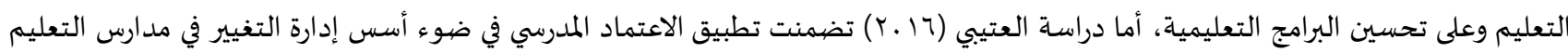
العام بمدينة الرياض.

أما من حيث المنهجية فقد تنوعت بين المنهج الوصفي والمنهج التحليلي، تم استخدام الاستبانة كأداة للدراسة كدراسة الأمير والعواملة

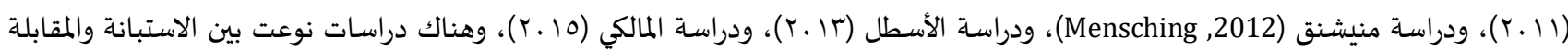

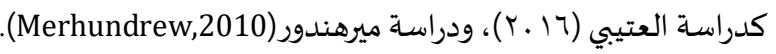

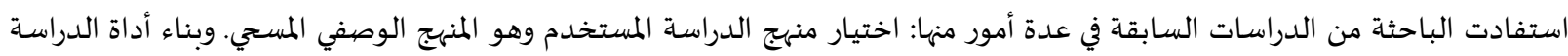

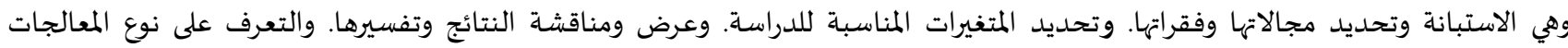

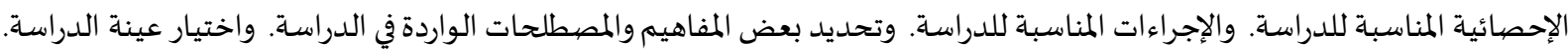
تتميز الدراساة الحالية عما سبقها من دراسات سابقة بأنها تناولت مجالات جديدة تم تطويرها من قبل الباحثة في مجال قياس معايير الاعتماد في المدارس الخاصية في الأردن. كما تتميز الدراسة الحالية عما سبقها من دراسات بتناولها موضوع معايير الاعتماد في مجال المدارس الخاصة ، والذي تعتبر من الدراسات

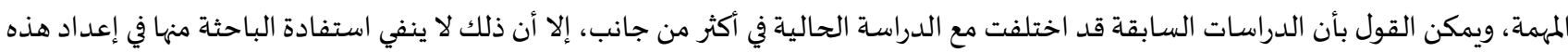

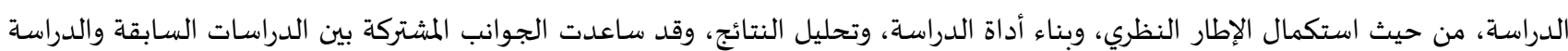

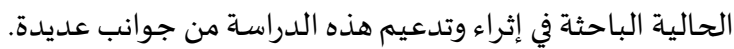

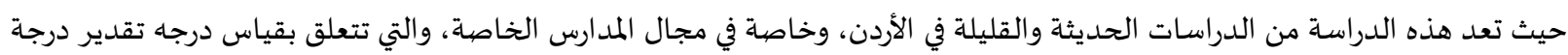

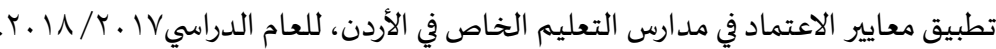

مشكلة الدراسـة وأسئلتها: نظرًا لأهمية تطبيق معايير الاعتماد المدرسي الدولي، ولما له من فوائد عديدة تكمن في إمكانية التحقق من جودتها واستعدادها للمساءلة والثقة

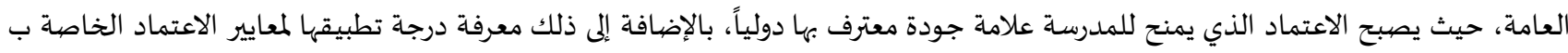
"منظمة الاعتماد الدولي(Accreditation International )، ولذلك فإن الدراسة الحالية حاولت إلقاء الضوء على تقدئ دادير درجة تطبيق معايير الاعتماد

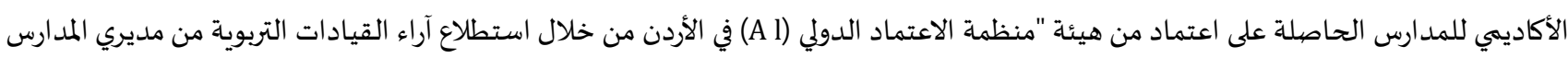
حول درجة تطبيق هذه المعايير، وتحديداً في المدارس الخاضيعة هينة لاعتماد الهيئة.

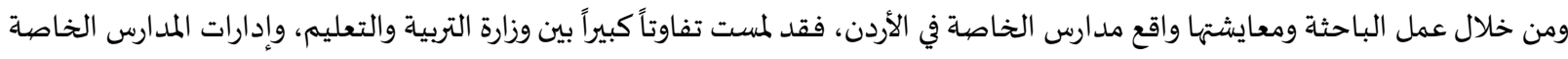
في تطبيق معايير الاعتماد الخاصة ب "منظمة الاعتماد الدولي(Al)، من حيث درجة تطبيق السلطة والإدارة، وتحقيق الرؤيا والفكر والرسالة القيادة والتنظيم، ودرجة توفر الموارد المالية، ومن حيث درجة ملائمة المرافق المدرسة، والموارد البشرية، والمكتبة ووسائل المعلومات والتكنولوجيا وغيرها من 
المعايير الخاضعة لمعايير الاعتماد. لذا سعت الباحثة دراسة موضوع معايير الاعتماد الخاصة ب "منظمة الاعتماد الدولي AI"، وذلك من أجل الكشف

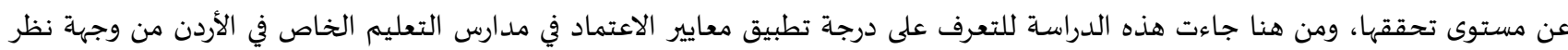
القيادات التربوية"؟ حيث تتمثل مشكلة الدراسة في تقدير درجة تطبيق معايير الاعتماد في مدارس التعليم الخاص في الأردن.

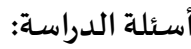

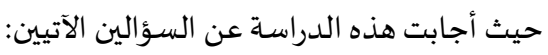

السؤال الأول: ما درجة تطبيق معايير الاعتماد في مدارس التعليم الخاص فئ في الأردان

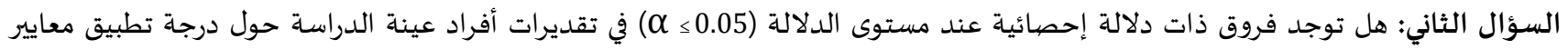

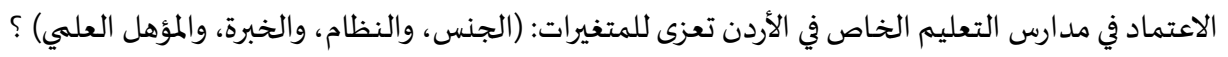

أهداف الدراسة:

هدفت هذه الدراسة لتحقيق الأهداف الآتياة:

التعرف إلى تقدير درجة تطبيق معايير الاعتماد في مدارس التعليم الخاص في الأردن.

التعرف إلى أثر المتغيرات الشخصية والوظيفية لأفراد عينة الدراسة (الجنس، والنظام، والخبرة، والمؤهل العلمي) في تقدير درجة تطبيق معايير

الاعتماد في مدارس التعليم الخاص في الأردن.

أهمية الدراسة:

تتضمن أهمية الدراسة جانبين هما: الأهمية النظرية والأهمية العملية، والمتمثلة بالآتي: الأهمية النظرية: تتضح أهمية هذه الدراسـة من خلال موضيوعها الذي يبحث بشكل مباشر وواضح في الكشف عن درجة تطبيق معايير الاعتماد في مدارس التعليم الخاص في الأردن. كما تبرز أهمية الدراسة من الناحية النظرية كونها تتناول موضوعاً متعلقاً بجودة التعليم، والذي يعد أحد أهم مؤشرات تقدم أي دولة، ألا

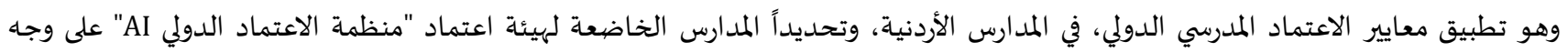

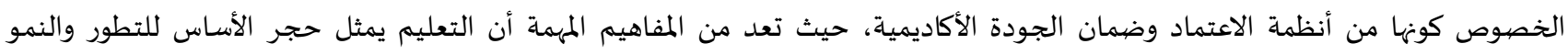
الاقتصادي والحضاري لأي دولة. كما توفر هذه الدراسة خلفية نظرية، ودراسات سابقة حول درجة تطبيق هذه المعايير في المدارس الأردنية المحلية والدولية، كما وتكتسب هذه

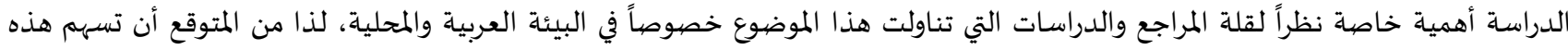
الدراسـة في إضافة أدبيات جديدة إلى الدراسات العربية عموماً والأردنية خصيوصاً، كونه التعليم يعتبر من أهم عوامل إحداث التهات التغيير في المجتمع وتنمية الموارد البشرية. الأهمية العملية: فقد تحددت أهمية هذه الدراسة من خلال الآتي:

دراسـة تقدير درجة تطبيق معايير الاعتماد الخاصة بهيئة اعتماد "AI". في المدارس التي تطبق هذه المعايير من وجهة نظر المديرين والمعلمين. قد تكمن أهمية الدراسـة مما تتوصل إليه الدراسة الميدانية من نتائج وتوصيات تساعد المعنيين في الأردن. قد تسهم هذه الدراسة بإثراء المعرفة النظرية والتطبيقية حول معايير الاعتماد الخاصة بهيئة اعتماد "AI". قد تسهم في تزويد صانعي القرار والسياسات التربوية في مديرية التعليم الخاص التابعة لوزارة التربية بمعايير الاعتماد العام ومدى انعكاس ذلك على جودة التعليم. من المؤمل أن يستفيد من هذه الدراسة الباحثون والمهتمون في هذا المجال، والتي قلما حظيت باهتمام الباحثين أو بحثت في دراسات سابقة،

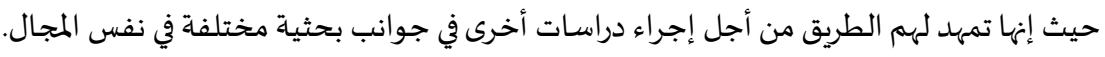

مصطلحات الدراسـة:

اشتملت الدراسة الحالية على مجموعة من التعريفات المتعلقة بموضورعات الدراسة، حيث تم تعريفها اصطلاحياً وإجرائياً كما يأتي: • الاعتماد الأكاديمي Academic Accreditation: تم تعريفه على أنه "مكانة أكاديمية أو وضع أكاديمي علمي يمنح للمؤسسة التعليمية أو البرنامج

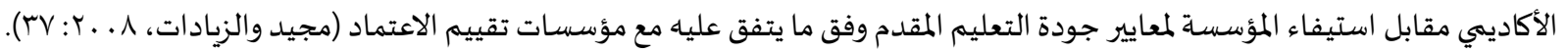


ويعرف الاعتماد الأكاديمي إجرائياً: بأنه عبارة عن عملية تقويم أداء المدارس بواسطة هيئة متخصصة في ضوء معايير الاعتماد الأكاديمي. وهو أيضًا بيان

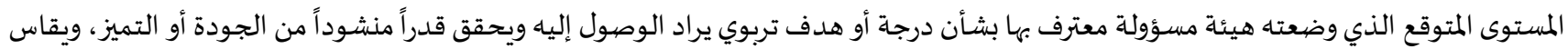

من خلال استجابات أفراد عينة الدراسة (مدراء) على فقرات الاستبانة التي تسهم بتطويرها.

• التعليم الخاص Private education هي كل مؤسسة تعليمية أهلية اشتملت على صف أو أكثر من مراحل التعليم العام بأنواعـه المختلفة ويتعلم

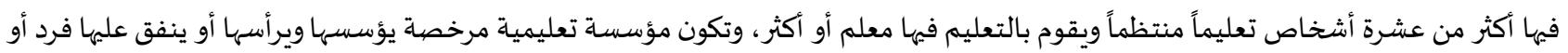

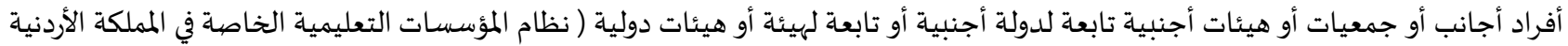

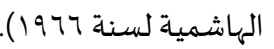

وتعرف إجرائياً بالمؤسسة التعليمية الخاصة التي يشرف عليها القادة التربويين والذين هم من تم تطبيق أداة الدراسة عليهم. • هيئة الاعتماد Accreditation Body : جهة رسمية حكومية أو دولية معترف بها في الأردن تمنح تراخيص تطبيق البرامج التعليمية المختلفة

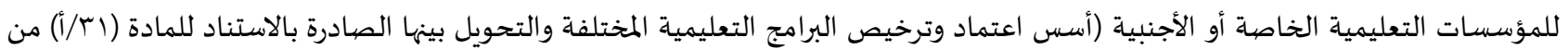

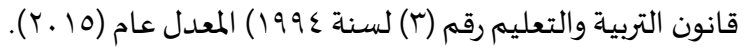
• القيادات التربوية Educational leaders : تعرف إجرائياً: بالقادة التربويين(التربويين) في المدارس الخاصية والمعتمدة دولياً.

حدود الدراسة: اشتملت حدود الدراسة على الآتي: الحدود الموضوعية: اقتصرت الدراسـة على جمع البيانات الأولية لتحليل تقدير درجة تطبيق معايير الاعتماد في المدارس الخاصة في الأردن . الحدود المكانية : اقتصرت الدراسة على المدارس الخاصة في الأردن. الحدود البشرية : اقتصرت الدراسة على القيادات التربوية ( مديري المدارس الخاصة).

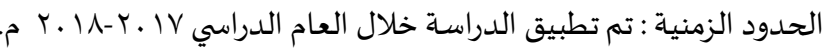

محسددات الدراسـة:

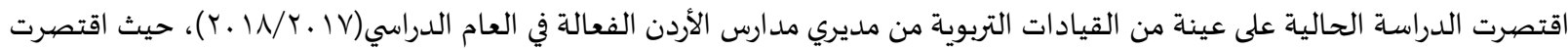

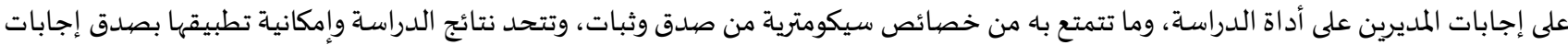
أفراد عينة الدراسـة وصداس مقياس الدراسـة.

منهجية الدراسـة: لتحقيق أهداف الدراسة تم استخدام المنهج الوصفي المسسج، وذلك لملاءمته لهذه الدِّراسة والإجابة عن أسئلتها، ولتحقيق أهد افها.

مجتمع الدراسة وعينتها:

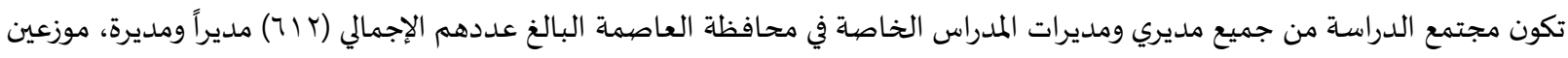

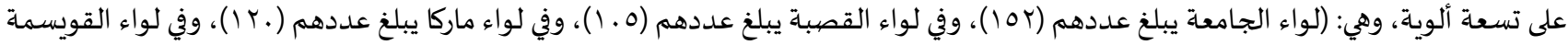

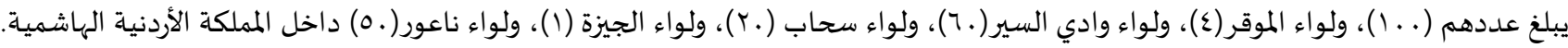

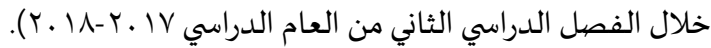

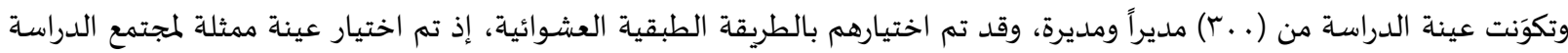

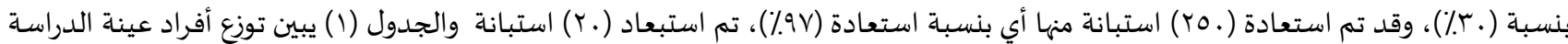
حسب المتغيرات المستقلة. 
جدول (1) : توزيع أفراد عينة الدراسة تبعاً لمتغيرات الدراسة: (النظام، والمؤهل العلمي، والجنس، سنوات الخبرة)

\begin{tabular}{|c|c|c|c|}
\hline النسبة & التكرار & الفئات & المتغيرات \\
\hline$\Delta r, r$ & r. 1 & أردني & النظام \\
\hline 17,1 & $\varepsilon r$ & أجنبي & \\
\hline IT,. & $r$ r. & ذكر & الجنس \\
\hline$\wedge$, & rr. & أنثى & \\
\hline$r 1,7$ & $0 \varepsilon$ & بكالوريوس & المؤهل العلمي \\
\hline $0 \wedge, \wedge$ & $1 \leqslant Y$ & ماجستير & \\
\hline 19,7 & $\varepsilon 9$ & دكتوراه & \\
\hline 10,7 & $r q$ & م سنوات فما دون & سنوات الخبرة \\
\hline or, r & Tr & من ه - اقل من ـ ا سنوات & \\
\hline$r 1, r$ & $\mathrm{vi}$ & . 1 سنه فأكثر. & \\
\hline $1, \ldots$, & ro. & \multicolumn{2}{|c|}{ المجموع } \\
\hline
\end{tabular}

تم بناء أداة الدراسة بعد الرجوع إلى معايير الاعتماد المدرسي حسب وثيقة وزارة التربية والتعليم للمدارس الخاصة في الأردن للعام

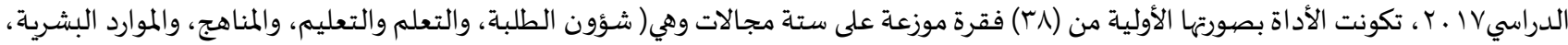

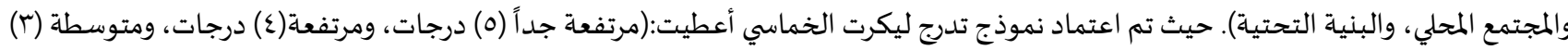

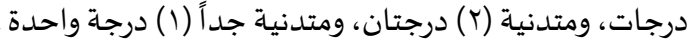

صدل صدق أداة الدراسة: صيدق المحتوى: تم التأكد من صهدق المحتوى للأداة، حيث تم عَرضُها على عدد من المحكمين من ذوي الخبرة والاختصاص من أعضياء هيئة التدريس في

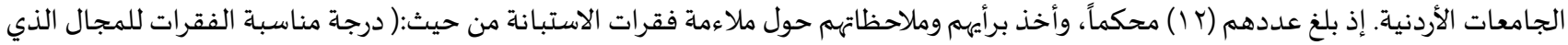

تندرج تحته، ووضوح الفقرات، ودرجة دقة وسلامة الصياغة اللغوية).

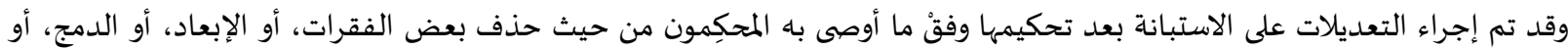
إعادة الصياغة، وبلغ مجموع فقرات الاستبانة بعد التحكيم (rس) فقرة، موزعة على مجالات وفقرات الاستبانة، والمتمثلة بالآتي: المجال شؤون الطلبة: حيث تكونت بصورتها النهائية من(0 ) فقرات. المجال التعلم والتعليم: حيث تكونت بصورتها النهائية من(7) فقرات. المجال المنهاج: حيث تكونت بصورتها الههائية من( (7) فقرات.

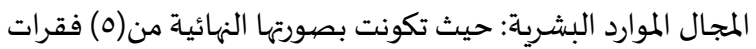
المجال المجتمع المحلي: حيث تكونت بصورتها النهائية من (7) فقرات. المجال البنية التحتية: حيث تكونت بصيورتها النهائية من(0) فقرات.

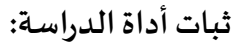
للتأكد من ثبات أداة الدراسـة، فقد تم التحقق بطريقة الاختبار واعادة الاختبار (test-retest) بتطبيق المقياس، واعادة تطبيقه بعد أسبوعين

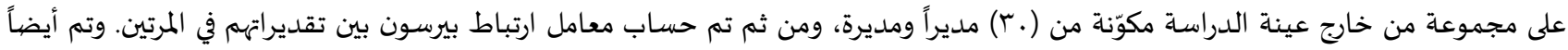

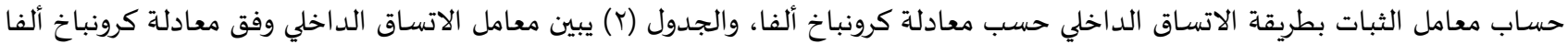
وثبات الإعادة للمجالات والأداة ككل واعتبرت هذه القيم ملائمة لغايات هذه الدراسـة.

جدول (Y): معامل الاتساق الداخلي كرونباخ ألفا وثبات الإعادة للمجالات والدرجة الكلية

\begin{tabular}{|c|c|c|}
\hline الاتساق الداخلي & ثبات الإعادة & المجال \\
\hline$\cdot, \vee \vee 9$ & •, $\wedge \varepsilon$ & شؤون الطلبة \\
\hline$\cdot, 10$ & $\cdot, \lambda \mathrm{V}$ & التعلم والتعليم \\
\hline ., $(1)$ & •, & المنهاج \\
\hline ., 11 & $\cdot, \Lambda$ & الموارد البشربة \\
\hline ., $\mathrm{V}$. & $\cdot, 10$ & المجتمع المحلي \\
\hline$\cdot, \wedge \varepsilon$ & $\cdot, \wedge \varepsilon$ & البنية التحتية \\
\hline$\cdot, 91$ & . 9 . & معايير الاعتماد ككل \\
\hline
\end{tabular}




\section{معيارتصحيح أداة الدراسـة:}

تم اعتماد تدرج ليكرت الخماسي لتصحيح أدوات الدراسة، بإعطاء كل فقرة من فقراته درجة واحدة من بين درجاته الخمس (مرتفعة جداً،

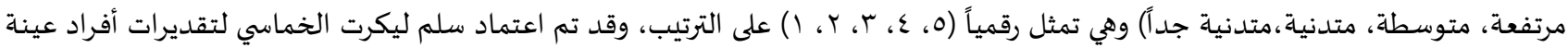

\begin{tabular}{|c|c|}
\hline منخفضية & T,rT-1 \\
\hline متوسطة & $r, T V-r, r \varepsilon$ \\
\hline كبيرة & $0-r, 4 \Lambda$ \\
\hline
\end{tabular}

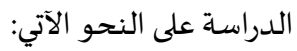

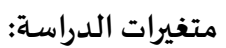

اشتملت الدراسة الحالية على المتغيرات الآتية:

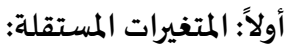

النظام: وله فئتان: أردني، أجنبي

الجنس: وله فئتان : ذكر، أنثى

سنوات الخبرة: وله ثلاثة فئات:(0 سنوات فما دون)، (اكثر من ه- اقل من • ا سنوات)، (أكثر من • ا سنوات).

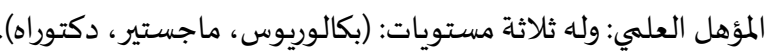

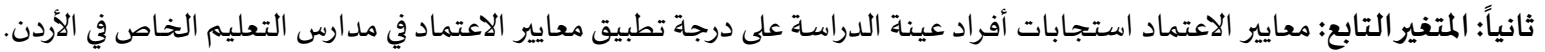

إجراءات الدراسـة:

بعد الاطلاع على الأدب النظري والدراسات السابقة ذات العلاقة بمعايير الاعتماد في مدارس التعليم الخاص في الأردن، تم بناء وتحكيم أداة

الدراسـة، وصياغتها بشكلهما النهائي، ولتحقيق هدف الدراسة، تم القيام بالإجراءات الآتية:

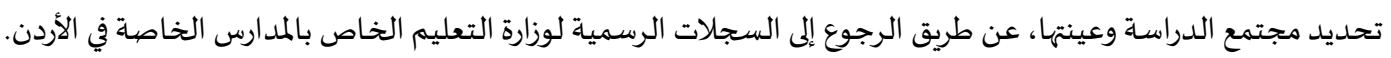

توزيع أداة الدراسـة على أفراد عينة الدراسة.

جمع استبانات أداة الدراسـة وترتيها، والتأكد من صلاحيتها لأغراض التحليل الإحصائي عن طريق استخدام نظام(SPSS)، للمعالجات الإحصائية،

بهدف استخراج النتائج، والإجابة على أسئلة الدراسـة. بعد تفريخ إجابات أفراد عينة الدراسة عن فقرات الأداة .

المعالجة الإحصيائية:

للإجابة عن السؤال الأول تم استخراج المتوسطات الحسابية والانحرافات المعيارية لدرجة تطبيق معايير الاعتماد في مدارس التعليم الخاص في

الأردن من وجهة نظر القيادات التربوية (مدراء المدارس).

للإجابة عن السؤال الثاني: تم استخراج المتوسطات الحسابية والانحرافات المعيارية وتحليل التباين الأحادي والمقارنات البعاديات البادية شيفيه لاستجابات أفراد العينة حول درجة تطبيق معايير الاعتماد في مدارس التعليم الخاص في الأردن من وجهاة نظر القيادات التربوية تبعاً لمتغيرات

(النظام، والجنس، والمؤهل العلمي، وسنوات الخبرة).

\section{عرض نتائج الدراسـة:}

هدفت هذه الدراسة الكشف عن درجة تطبيق معايير الاعتماد في مدارس التعليم الخاص في الأردن من وجهة نظر القيادات التربوية(مدرائها)،

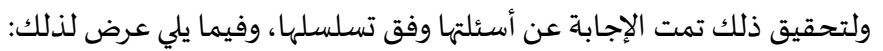

نتائج السؤال الأول: ما درجة تطبيق معايير الاعتماد في مدارس التعليم الخاص في في الأردن من وجهة نظر القيادادات التربوية؟ للإجابة عن هذا السؤال تم استخراج المتوسطات الحسابية والانحرافات المعيارية لدرجة تطبيق معايير الاعتماد في مدارس التعليم الخاص في الأردن من وجهة نظر القيادات التربوية، والجدول الآتي يوضح ذبراس ذلك. 
جدول (r): المتوسطات الحسابية والانحر افات المعيارية لدرجة تطبيق معايير الاعتماد في مدارس التعليم الخاص في الأردن من وجهة نظر القيادات التربوية

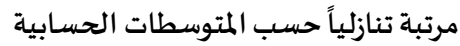

\begin{tabular}{|c|c|c|c|c|c|}
\hline الدرجة & الانحراف المعياري & المتوسط الحسابي & المجال & الرقم & الرتبة \\
\hline كبيرة &.,$\varepsilon 1$ & $\varepsilon, . \varepsilon$ & شؤون الطلبة & 1 & 1 \\
\hline كبيرة &., 0 . & $\varepsilon, . Y$ & البنية التحتية & 7 & r \\
\hline كبيرة & . or & $r, v \wedge$ & التعلم والتعليم & r & $r$ \\
\hline كبيرة & . & $r, 7 \vee$ & المنهاج & r & $\varepsilon$ \\
\hline كبيرة &.,$\varepsilon V$ & $r, 77$ & الموارد البشرية & $\varepsilon$ & 0 \\
\hline كبيرة & . & $r, \varepsilon \varepsilon$ & المجتمع المحلي & 。 & 7 \\
\hline كبيرة & . ro & $r, \mathrm{~V}$ & \multicolumn{2}{|l|}{ معايير الاعتماد الكلي } & \\
\hline
\end{tabular}

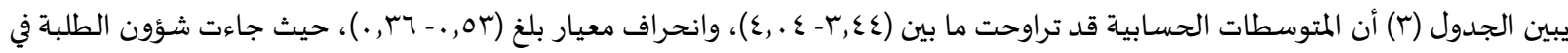

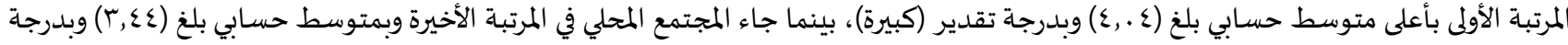

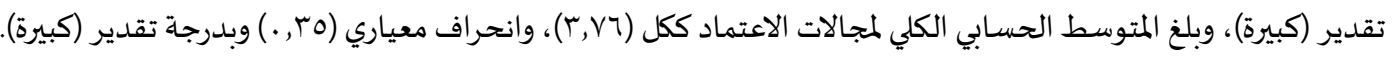
وقد تعزى هذه النتيجة حسب تقديرات عينة الدراسة أن درجة تطبيق معايير الاعتماد الأكاديمي في المؤسسة التربوية، ودورها في تعزيز وتطوير

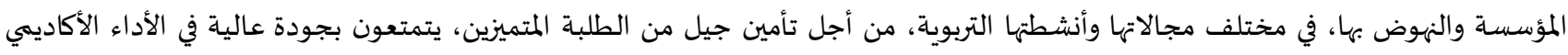

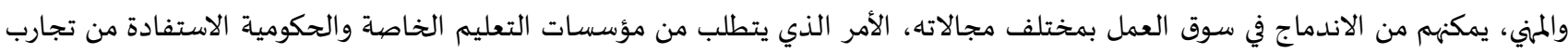

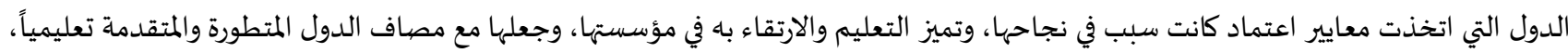

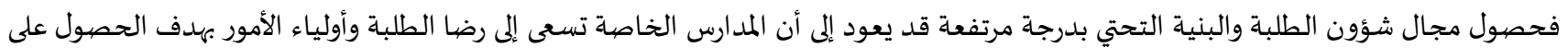
العائد المادي.

وقد تعزى هذه النتيجة الكبيرة حسب تقديرات عينة الدراسة إلى معاناة الأردن من ضعف في إدارتها المالية، وضعف في الحوافز المقدمة لهم التي

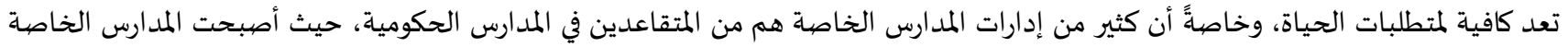

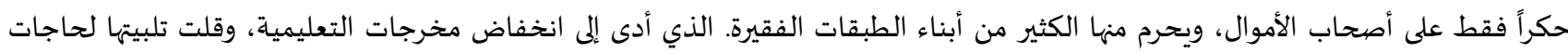

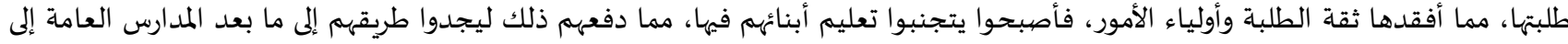
المدارس الخاصة،، التي تتمتع بنظام تعليمي أفضل يهتم بتفوق الطالب في المناهج التي يدرسهاء فقد جاء الاهتمام بالنظام التعليمي التربوي وتحسينه وتطويره، كونه المقياس الحقيقي لحضارة الأمة في الوقت الحالي، والذي من خلاله

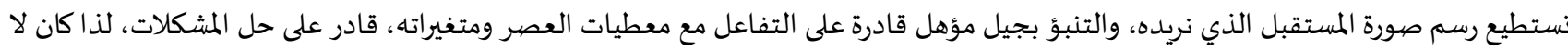

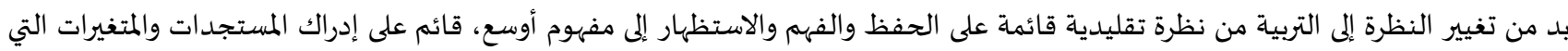

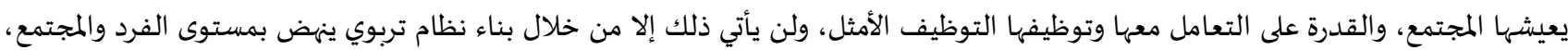

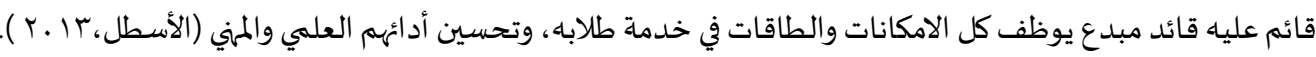
وتتفق هذه النتيجة الكبيرة حسب تقديرات عينة الدراسة مع ما أشار إليه بلسوبري (Pillsbury,2012) أن مجال الجودة والاعتماد في التعليم أصبح من القضايا الرئيسة على المستوى العالمي في تقييم المدارس من أجل تحقيق تطوير وإصلاح نوعي في النظام التعليهي بجميع عناصره ومستويتوياتها ، إضافة إلى أها تشجع المدارس على الارتقاء بمعايير جودة التعليم، والمساهمة في تحسين أوضاع البلدان التي تنتمي إليها، بما يعزز نجاح الطلاب وضمان

مستقبلهم.

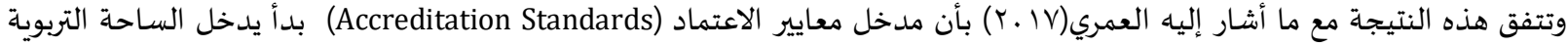

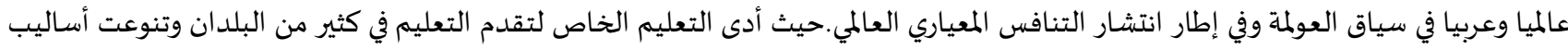
التعليم والعلوم والمعارف التي أصبحت تدرس في المدارس والمعاهد الأهلية، ويستفيد من التعليم الخاص عدة المدئ فئات من المجتمع، منهم المعلمين في

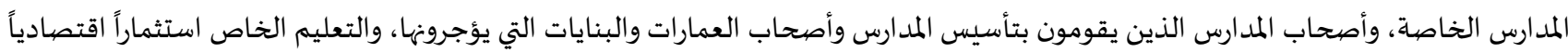

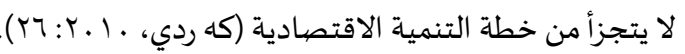
ومثلت معايير جودة التعليم هدفاً مركزياً منظوراً لكافة فعاليات التربية، وما انفكت اليونسكو منذ أكثر من عقد مضيى تلح في كافة مؤتمراتها

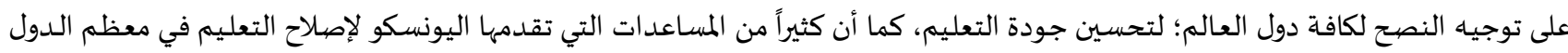

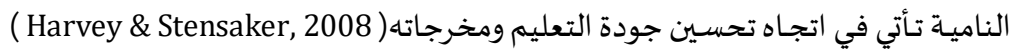

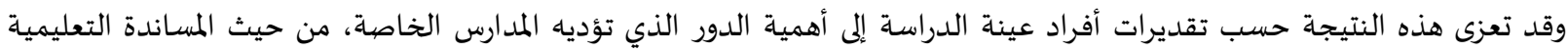
وإسهامها في سد الاحتياجات التربوية في المجتمع الذي لا يستطيع التعليم الحكومي القيام بها، وخاصة لبعض الأهالي مثل إتباع أساليب جديدة في 
التدريس، أو التقليل من عدد الطلبة في الصف الواحد، بهدف زيادة التحصيل العلمي للطلبة، وزيادة اهتمام المعلم بطلابه، كما يبرز دور المدارس

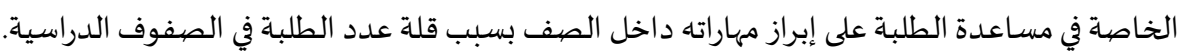

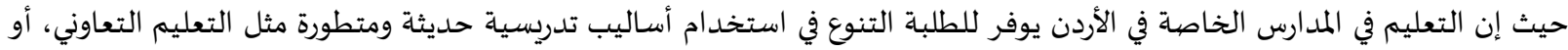

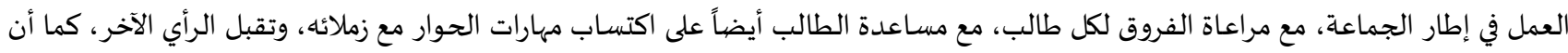

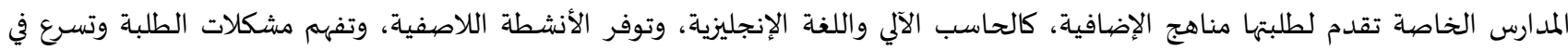
مساعدتهم على إيجاد حلول مناسبة لها. وقد تعزى هذه النتيجة الكبيرة إلى أن المدارس الخاصة جاءية إساء استجابةً لمواكبة التغيرات العلمية والتكنولوجية والإقبال المتزايد على التعليم، ومن أجل تقليل الضغوطات على التعليم في المجال الحكومي، وفي هذا السياق تتفق هذه النتيجة المرتفعة حسب تقديرات عينة الدراسة مع ما أشار

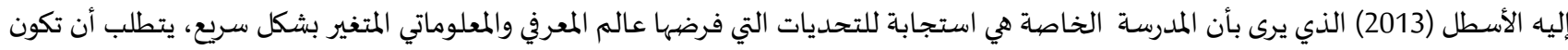

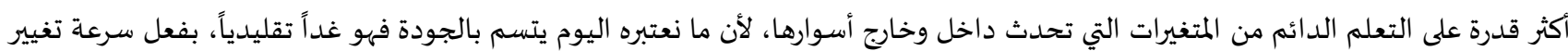
المعرفة، وتجديد احتياجات المستفيدين (طلاب، ومعلمين، وأولياء أمور، والمجتمع، وأصحاب المات الأعمال).

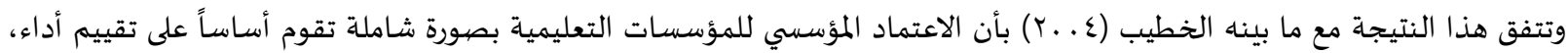
والإقرار بأحقيتها في تقديم خدمة تعليمية طبقاً لمعايير محددة، ويطلق عليه أيضاً بالاعتماد العام أو الاعتماد الأولي، وهو بمثابة القاعدة الأسـاسية لأي الأي نوع من أنواع الاعتماد الأخرى، كما يعتبر الخطوة الضرورية للبدء في التأكد من أن المؤسسة التعليمية بكافة عناصرها(المدخلات، العمليات،

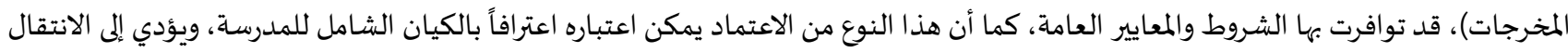
إلى الأكاديمي أو البرنامجي.

فقد بينت وزارة التربية والتعليم الأردنية القطاع الخاص (10 ـ ب)، والتي تشمل بوجود رسالة مؤسسية مناسبة لمستواها كمؤسسة تعليمة، وأن

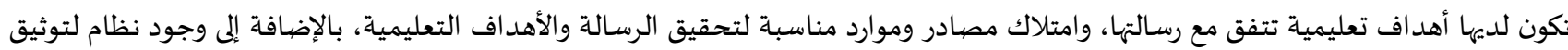

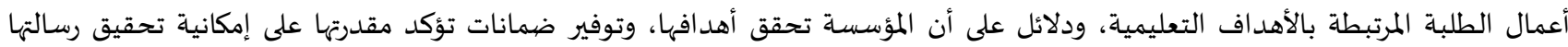
وأهدافها.



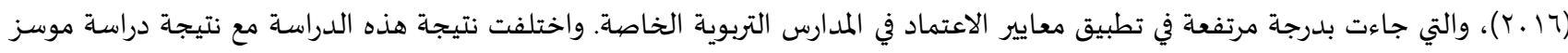

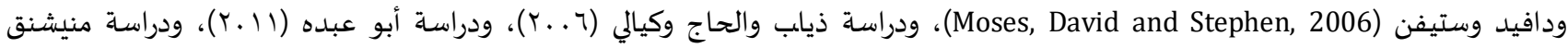

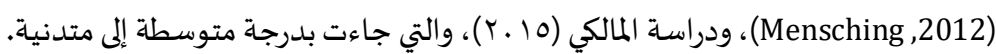
وقد تم حساب المتوسطات الحسابية والانحرافات المعيارية لتقديرات أفراد عينة الدراسة على فقرات كل مجال على حدة، حئه حيث كانت على الى النحو التالي:

\section{المجال الأول: شؤون الطلبة}

تم حساب المتوسطات الحسابية والانحرافات المعيارية لفقرات مجال(شؤون الطلبة) حول تطبيق معايير الاعتماد في مدارس التعليم الخاص في

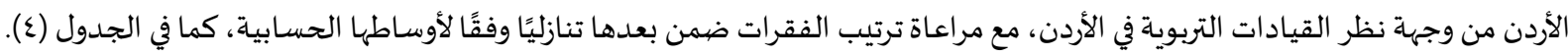
جدول (ع): المتوسطات الحسابية والانحرافات المعيارية للفقرات المتعلقة بمجال (شؤون الطلبة) مرتبة تنازلياً حسب المتوسطات الحسابية

\begin{tabular}{|c|c|c|c|c|c|}
\hline 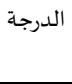 & الانحراف المعياري & الحسابي & 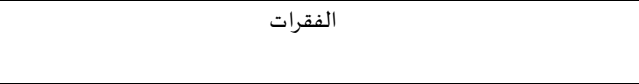 & 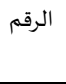 & 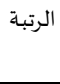 \\
\hline كبيرة &., 07 & $\varepsilon, 0 \mathrm{~V}$ & يتم الاحتفاظ بملف خاص لكل طالب لحفظ بياناته & r & 1 \\
\hline كبيرة &., 07 & $\varepsilon, r \varepsilon$ & يطبق على جميع الطلبة معايير القبول المعتمدة & $\varepsilon$ & $r$ \\
\hline كبيرة &., 71 & $\varepsilon, \cdot V$ & تُحدث الملفات الخاصة بالطلبة باستمرار & 1 & $r$ \\
\hline كبيرة &., $\mathrm{OV}$ & $r, v i$ & يوظف الطلبة مهاراتهم القيادية من خلال إشراكهم بالأنشطة التي تعزز دورهم & $\circ$ & $\varepsilon$ \\
\hline كبيرة & $\cdot, 7$ & $r, 0$. & يوظف الطلبة مهاراتهم في الاتصال & r & $\circ$ \\
\hline كبيرة & . & $\varepsilon, . \varepsilon$ & شؤون الطلبة & & \\
\hline
\end{tabular}

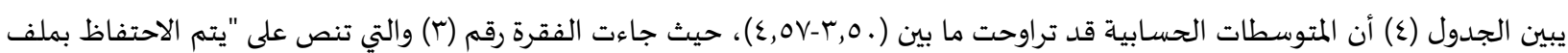

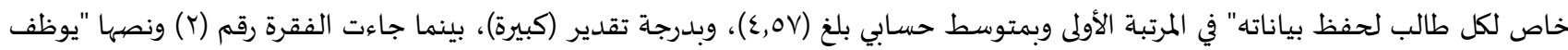

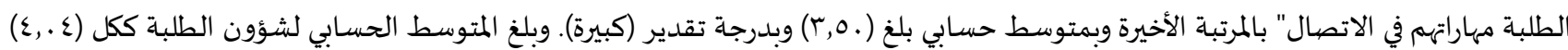
وبدرجة تقدير (كبيرة). 
وقد تعزى هذه النتيجة حسب تقديرات عينة الدراسة إلى الدور الذي يقوم به مدير المدرسة بدور فاعل في مجال " شؤون الطلبة " من أجل إنجاح

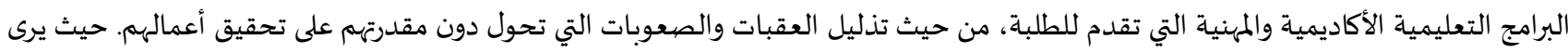

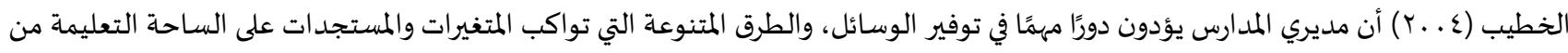

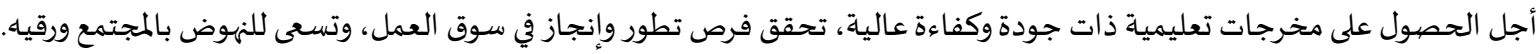

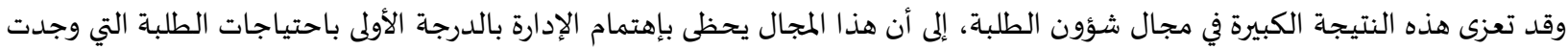

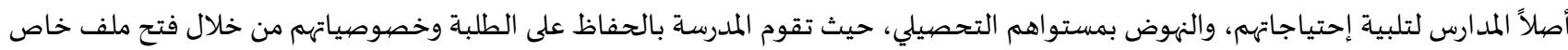

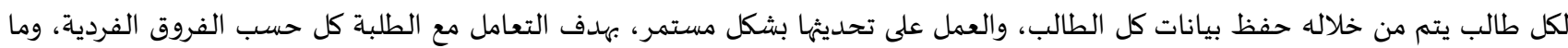
يتناسب احتياجاته التعليمياة والتحصيلية، من أجل تأمين تعليم يحقق التطور والإنجاز لكل الطلبة، وتتفق هذه النتيجة مع ما أشارت إليه الفقرة رقم

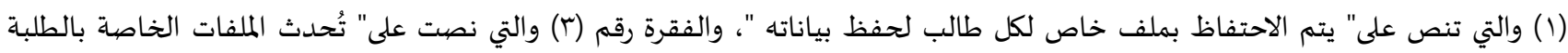
باستمرار" . كما أن المدارس الخاصة تهدف من إرسال أولياء الأمور أبنائهم إلى المدارس الخاصة،، لثقتهم بأن المدارس الخاصة توفر التعليم ومستلزماته لجميع

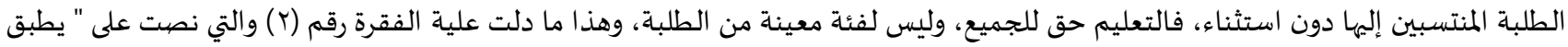
على جميع الطلبة معايير القبول المعتمدة". كما أن المدارس الخاصة تسعى جاهدة إلى تلبية احتياجات الطلبة التي هم الفئة الأسـاسية في المدرسة والتي هم بناة المستقبل وقيادتها، لذا

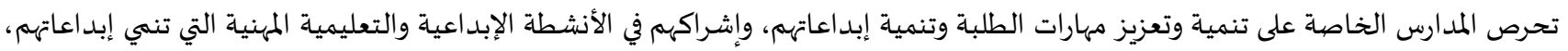

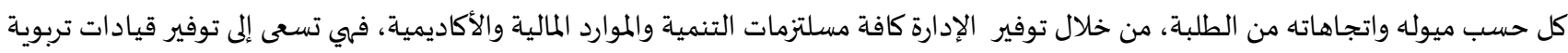
تتمتع بالكفاءة والمهارة التعليمية والقيادة العالية التي تستطيع تلبية إحتياجات الطاتهات الطلبة.

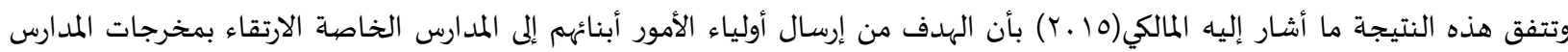
الثانوية بما يتواءم مع احتياجات سوق العمل، من خلال تجويد التعليم وتحسين كفايات الخريجين.

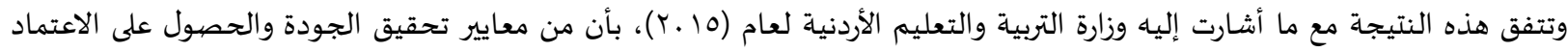

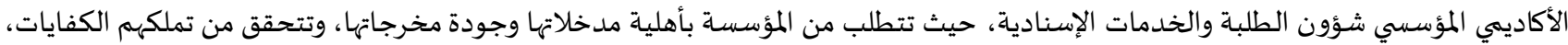

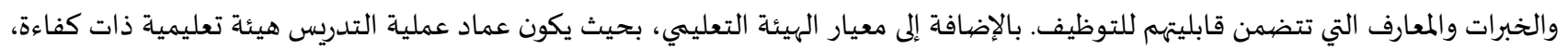

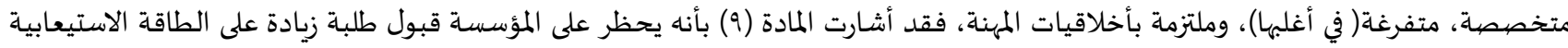

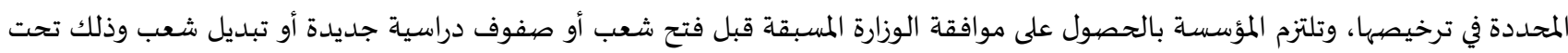

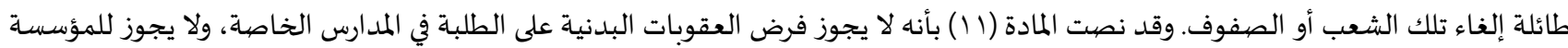
حجز ملف أي طالب أو حرمانه من التعليم. كما أشـار المعيار السادس الخاص بشؤون الطلبة: حسب تقديرات عينة الدراسة إلى الإهتمام بالطلبة وتلبية احتياجاتهم من خلال التنوع في

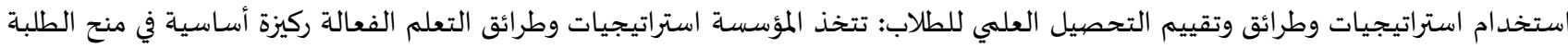

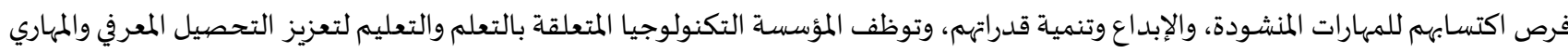
للطلبة وفق متطلبات وطبيعة كل برنامج أكاديمي، وتطبق الهيئة التعليمية مقاييس واضحة، ومتنوعة لتقييم، وتحليل مدى اكتساب الطلبة لنواتج

التعلم.

أما بالنسبة للفقرة الأخيرة (7) التي نصت على (يوظف الطلبة مهاراتهم في الاتصال)، والتي جاءت بدرجة متوسطة، والتي كشفت عن دور المدرسة

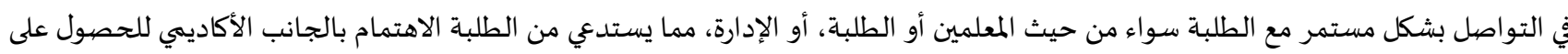
تحصيل علمي عالي.

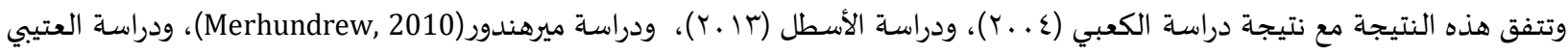

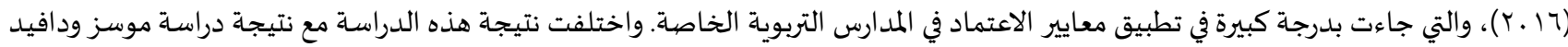

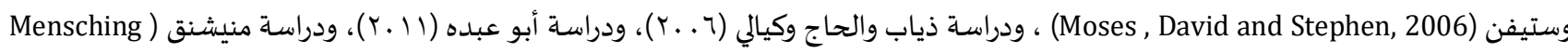
2012,)، ودراسة المالكي (10 • (Y)، والتي جاءت بدرجة متوسطة إلى قليلة.

المجال الثاني: البنية التحتية (الموارد المادية )

تم حساب المتوسطات الحسابية والانحرافات المعيارية لفقرات مجال (البنية التحتية) حول تطبيق معايير الاعتماد في مدارس التعليم الخاص في

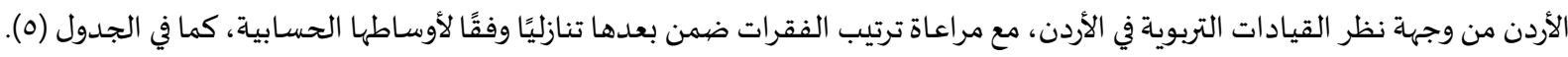




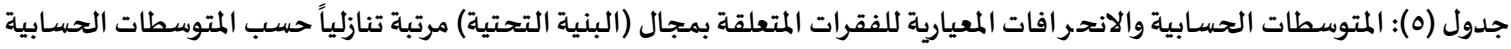

\begin{tabular}{|c|c|c|c|c|c|}
\hline 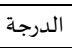 & الانحراف المعياري & المتوسط الحسابي & الفقرات & 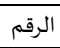 & 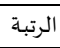 \\
\hline كبيرة &., $0 \mathrm{~T}$ & $\varepsilon, r_{0}$ & تتمتع الصفوف بإضاءة وتهوية جيدة & 1 & 1 \\
\hline كبيرة &., $7 \varepsilon$ & $\varepsilon, r$. & تتناسب مساحة الصفوف مع أعداد الطلبة & $r$ & $r$ \\
\hline كبيرة &., 07 & $\varepsilon, r)$ & تتسم بيئة المدرسة بأهها آمنة ونظيفة ومربحة & $r$ & $r$ \\
\hline كبيرة &., 70 & $r, \mathrm{rV}$ & تجري متابعة أعمال الصيانة الضرورية وبانتظام & $\varepsilon$ & $\varepsilon$ \\
\hline كبيرة & $\cdot, \mathrm{VA}$ & $r, \varepsilon \lambda$ & تساعد في الملاعب على ممارسة نشاطات التربية البدنية بشكل مناسب يستفاد & 0 & 0 \\
\hline كبيرة & ., 0. & $\varepsilon, . r$ & البنية التحتية & & \\
\hline
\end{tabular}

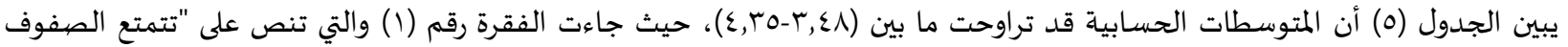
بإضاءة وتهوية جيدة" في المرتبة الأولى وبمتوسط حسابي بلغ (0٪,ع) وبدرجة تقدير (كبيرة)، بينما جاءت الفقرة رقم (0) ونصها "تسـاعد الملاعب على

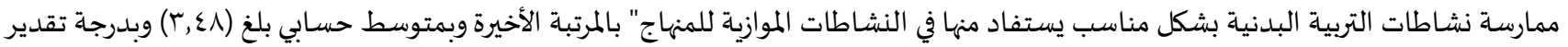
(كبيرة). وبلغ المتوسط الحسابي للبنية التحتية ككل (ץ . ,ع) وبدرجة تقدير (كبيرة).

وقد تعزى هذه النتيجة حسب تقديرات عينة الدراسة إلى الدور الذي يقوم بها إدارة المدارس الخاصة في مجال " البنية التحتية (الموارد المادية) "من أجل توفير مبنى مدرسي مناسب للطلبة، يتوفر فياه مستلزمات التكنولوجيا الحديثة، ومهيئ بوسائل وطرق صحية مناسبة، من حيث التهوية

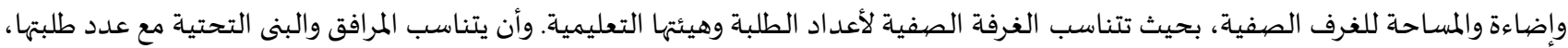
وهيئتها التعليمياة والإدارية، وعددد برامجها، وتتوخى المؤسسة إجراءات السلامة التامة في تسيير مرافقها وبناها التحتية، وهذا ما أشارت إليه الفقرة (ب)

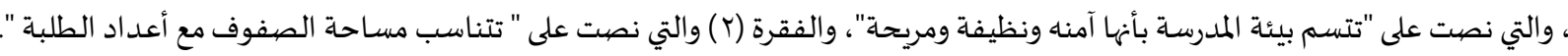

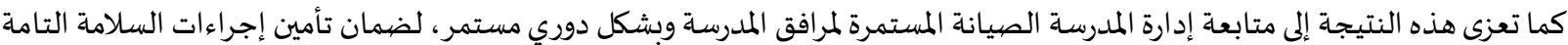

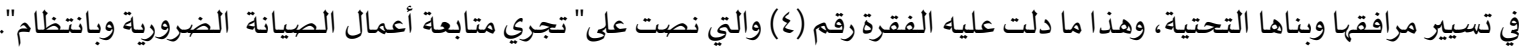

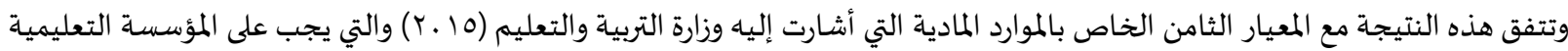

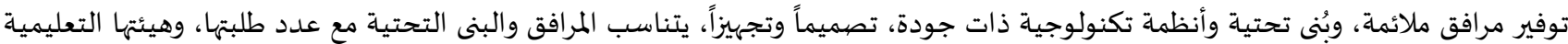

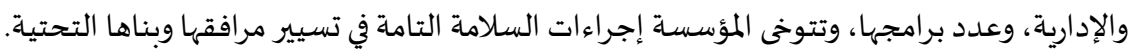

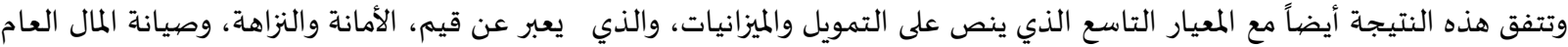

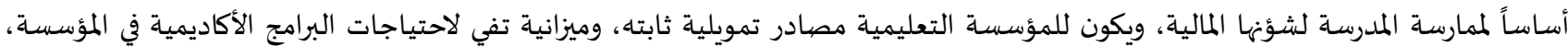
ومتطلبات السير الفعال، ولها نظام فعال في صرف الميزانياة، ومراقبة أوجه الصرف، بما يحقق الأهداف التي ينص علهها الإطار المؤسسي العام، وللمؤسسة استراتيجيات مالية (قصيرة، وطويلة المدي) تضهمن استقرارها المالي وتقليل المخاطر المالية. أما بالنسبة للفقرة الأخيرة (0) التي جاءت بدرجة متوسطة، والتي نصت على " تساعد الملاعب على ممارسة نشاطات التربية البدنية بشكل

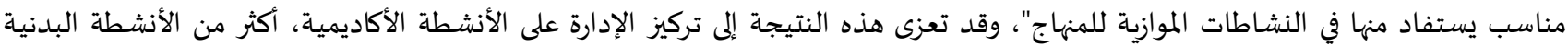

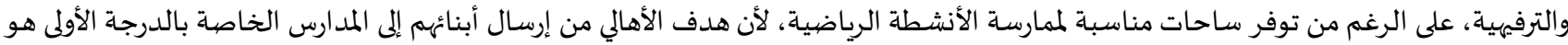
الهدف الأكاديمي والحصول على تحصيل علمي مرتفع.

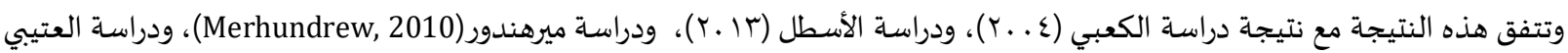
(7 ( إ)، والتي جاءت بدرجة مرتفعة في تطبيق معايير الاعتماد في المدارس التربوية الخاصة. واختلفت نتيجة هذه الدراسة مع نتيجة دراسة موسز

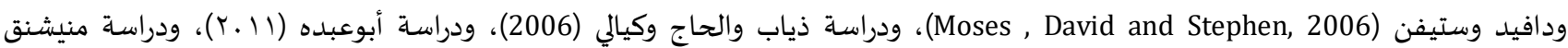
(2012, Mensching)، ودراسة المالكي (10 ـ (Y)، والتي جاءت بدرجة متوسطة إلى متدنية.

المجال الثالث: التعلم والتعليم تم حساب المتوسطات الحسابية والانحرافات المعيارية لفقرات مجال(التعلم والتعليم) حول تطبيق معايير الاعتماد في مدارس التعليم الخاص في الأردن من وجهة نظر القيادات التربوية في الأردن، مع مراعاة ترتيب الفقرات ضمن بعدها تنازليًا وفقًا لأوساطها الحسابية، كما في الجدول (7). 
جدول (7): المتوسطات الحسابية والانحر افات المعيارية للفقرات المتعلقة بمجال التعلم والتعليم مرتبة تنازلياً حسب المتوسطات الحسابية

\begin{tabular}{|c|c|c|c|c|c|}
\hline 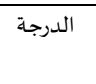 & المعياري & المسابي & 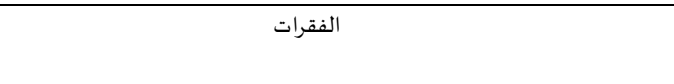 & 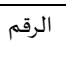 & 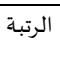 \\
\hline كبيرة & $\cdot, 71$ & $\varepsilon, r$ & يتم تهيئة الغرف الصفية المناسبة لعدد الطلبة & $r$ & 1 \\
\hline كبيرة & $\cdot, \mathrm{TV}$ & $\varepsilon, 11$ & يتم توفير معلمين مؤهلين في جميع المراحل التعليمية & 1 & $r$ \\
\hline كبيرة & $\cdot, \varepsilon 9$ & $\varepsilon, . r$ & يعي مدير المدرسة دوره الفني ويمارسه كمشرف مقيم & 7 & r \\
\hline كبيرة & $\cdot, \mathrm{VA}$ & $r, \Lambda$. & يتم استخدام تكنولوجيا التعليم في المدارس & r & $\varepsilon$ \\
\hline متوسطة & $\cdot, \mathrm{VI}$ & $r, r \varepsilon$ & يهتم المعلم بتطوير نفسه من خلال الاطلاع على أبرز المستجدات في مجال تخصصيه. & $\circ$ & $\circ$ \\
\hline متوسطة & $\cdot, \Lambda$ & $r, . r$ & يتم إشراك المعلمين بدورات تدريبة بشكل مستمر & $\varepsilon$ & 7 \\
\hline كبيرة & , or & $r, \mathrm{rA}$ & التعلم والتعليم & & \\
\hline
\end{tabular}

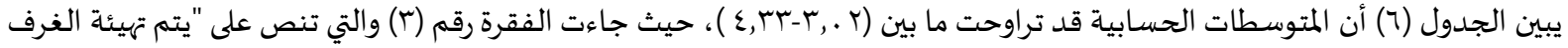

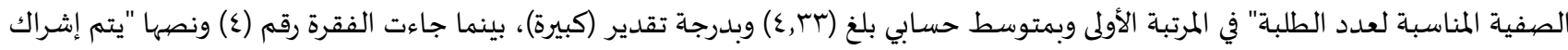

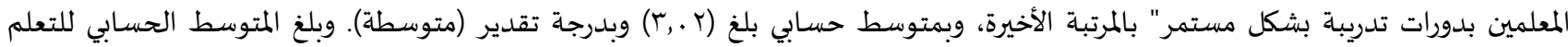
والتعليم ككل (r,VN) وبدرجة تقدير (كبيرة).

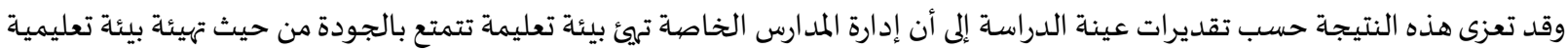

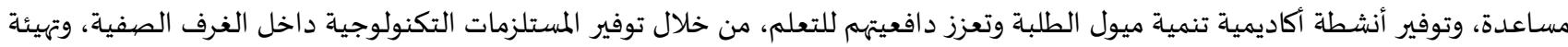

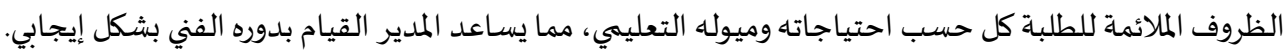

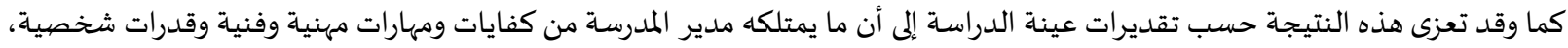

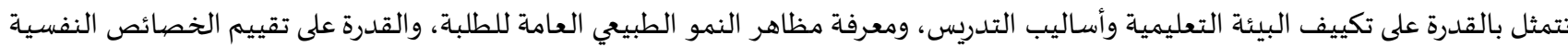

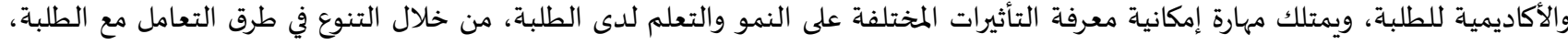

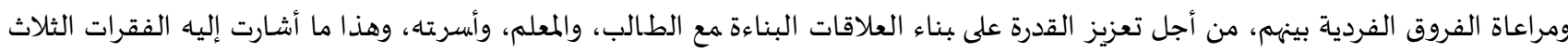

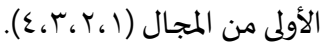

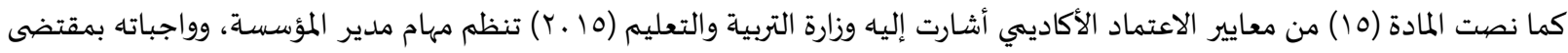

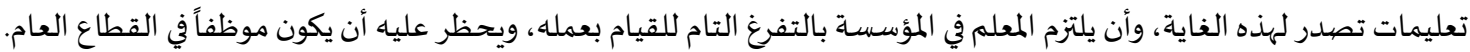

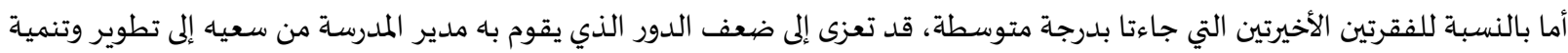

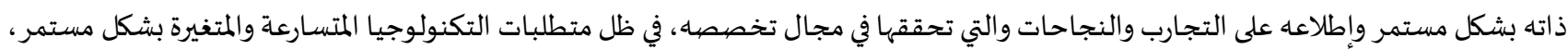

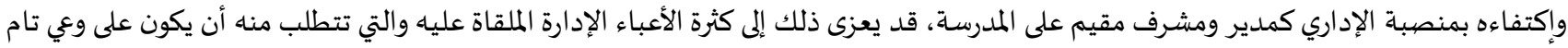

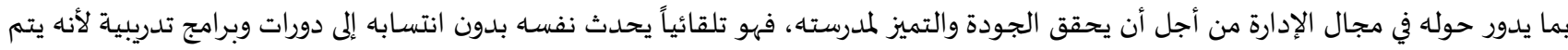
اختياره بناءً على كفاءته وخبراته الإدارية.

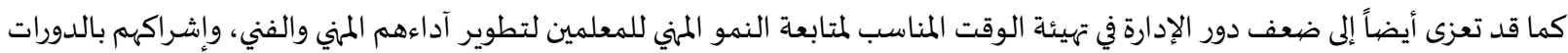

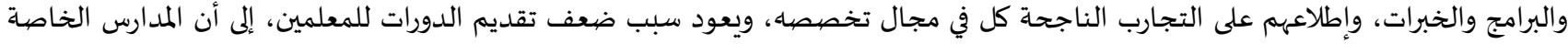

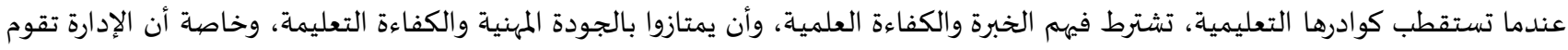

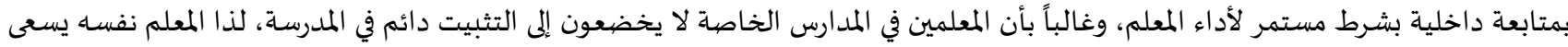

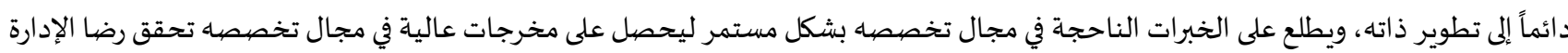
والأهالي منه.

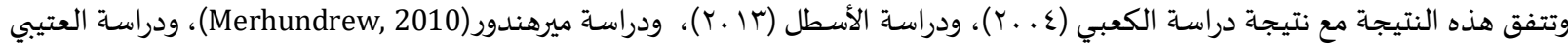

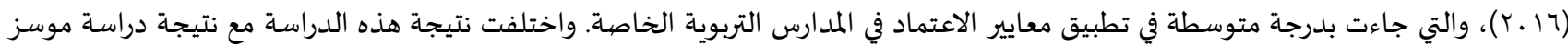

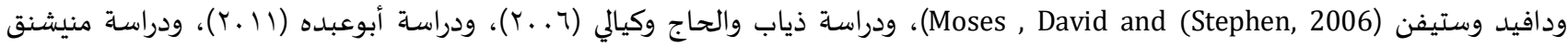
(Mensching 2012) و ودراسة المالكي (10 (Y) )، والتي جاءت بدرجة متوسطة إلى متدنية. المجال الرابع: المنهاج

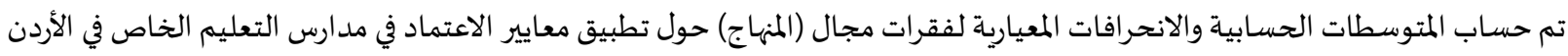

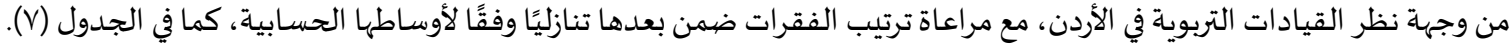


جدول (V): المتوسطات الحسابية والانحر افات المعيارية للفقرات المتعلقة بمجال المنهاج مرتبة تنازلياً حسب المتوسطات الحسابية

\begin{tabular}{|c|c|c|c|c|c|}
\hline 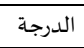 & الانحراف المعياري & المتوسط الحسابي & 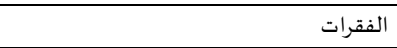 & 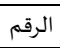 & 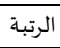 \\
\hline 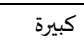 & $1, r v$ & $\varepsilon, r_{0}$ & يتم اعتماد المنهاج الأردني & 1 & 1 \\
\hline كبيرة &., $0 . \mathrm{V}$ & $r, \wedge V$ & تلبي الأهد اف حاجات المتعلم & r & r \\
\hline كبيرة &., 70 & $r, \Lambda T$ & ينوع المعلم في الأنشطة الصفية لإثراء المنهاج. & $\varepsilon$ & $r$ \\
\hline كبيرة & זות,. & $r, v q$ & تتمحور النشاطات والتكنولوجيا عن التعلم & $r$ & $\varepsilon$ \\
\hline متوسطة &., 71 & $r, r_{0}$ & يتم تشخيص جوانب الضعف والقوة من المنهاج & 7 & $\circ$ \\
\hline متوسطة &., 99 & $r, \Lambda r$ & يتم استخدام نظام حوسبة المناهج & 。 & 7 \\
\hline كبيرة &., 4 & $r, \mathrm{TV}$ & المنهاج & & \\
\hline
\end{tabular}

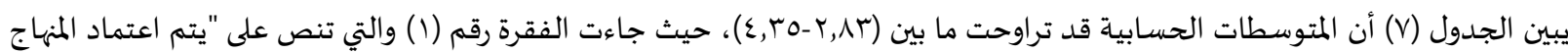

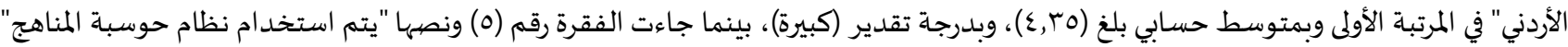

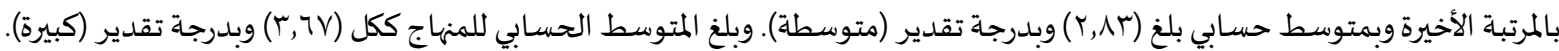

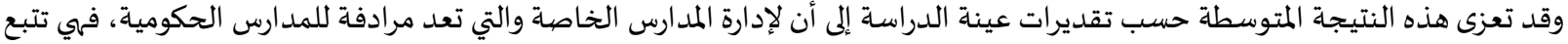

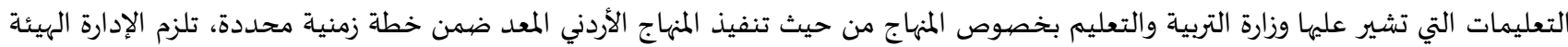

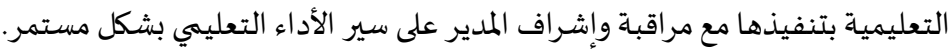

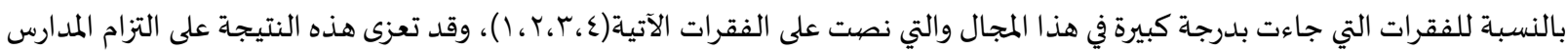

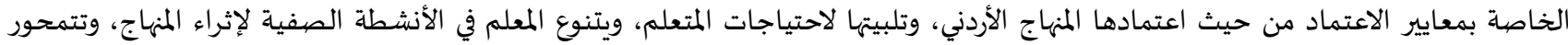

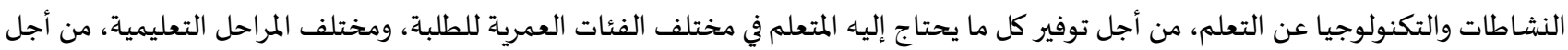

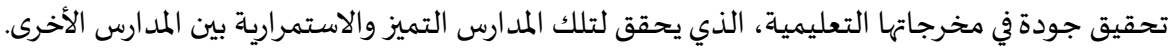

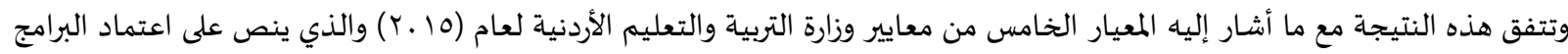

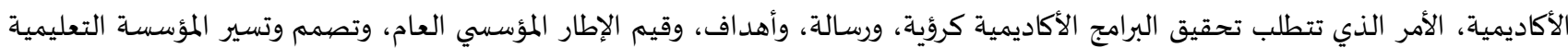

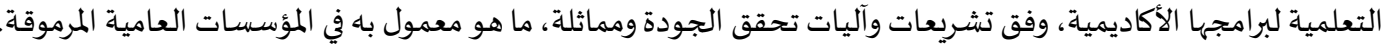

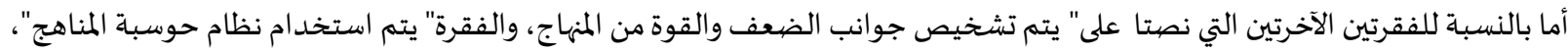
والتي جاءت بدرجة متوسطة إلى أن هذين الفقرتين يخصان القائمين على إعداد المنهاج في وزارة التربية وأن المدارس الخاصية مؤسسة تعليمية مرادفة

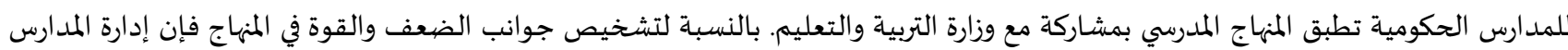
الخاصة تقوم بإعداد قائمة بالمجالات التي تشعر فهيا ضعف كمقترح، وتعرضها على القائمين على تنمية وتطوير المنهاج، ويمكن لإدارة المناهج إعتمادة والاستفادة منها. وتتفق هذه النتيجة مع نتيجة دراسة موسز ودافيد وستيفن (Moses , David and (Stephen, 2006) ، ودراسة ذياب والحاج وكيالي (T . . ) )،

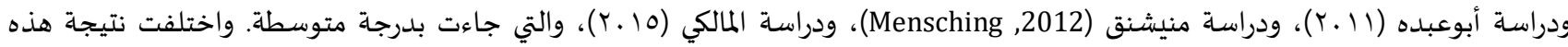

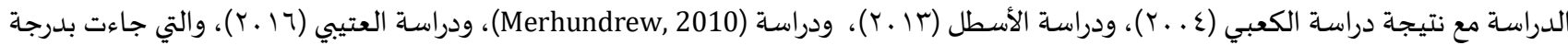
تقدير كبيرة في تطبيق معايير الاعتماد في المدارس التربوية الخاصة.

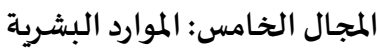
تم حساب المتوسطات الحسابية والانحرافات المعيارية لفقرات مجال (الموارد البشرية) حول تطبيق معايير الاعتماد في مدارس التعلئيم الخاص التحاص

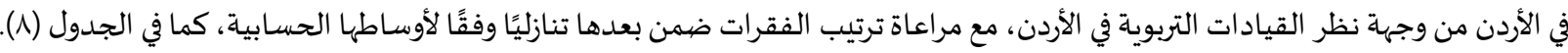

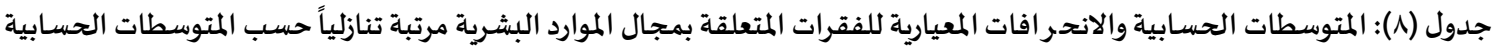

\begin{tabular}{|c|c|c|c|c|c|}
\hline 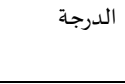 & المعياري & المسابي & 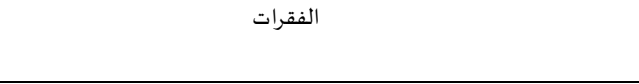 & 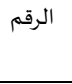 & 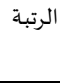 \\
\hline كبيرة & ., १. & $r, 9 r$ & يساعد الدعم الفني في تحقيق تعلم فعال & $\varepsilon$ & 1 \\
\hline كبيرة &., 7 . & $r, q$ & يبنى التطوير على حاجات الطلبة والمعلمين & $\circ$ & r \\
\hline كبيرة & . or & $r, \wedge \gamma$ & يمارس مدير المدرسة كمشرف مُقيم دوره الإداري في تحسين العملية التعليمية & 1 & r \\
\hline متوسطة & 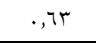 & r,o. & يشكل العاملون في المدرسة قادة للتغيير & r & $\varepsilon$ \\
\hline 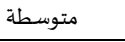 &., $\mathrm{VI}$ & r,ir & تطبق الإدارة المدرسية تفويض الصلاحيات بين العاملين & r & $\circ$ \\
\hline كبيرة & $\cdot, \varepsilon V$ & $r, 77$ & الموارد & & \\
\hline
\end{tabular}

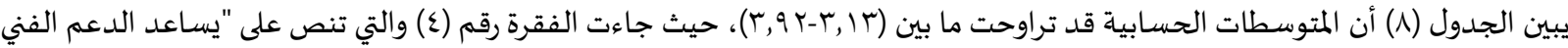

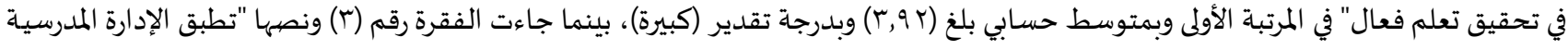


تفويض السلطات والصلاحيات بين العاملين" بالمرتبة الأخيرة وبمتوسط حسابي بلغ (r, (r) وبدرجة تقدير (متوسطة). وبلغ المتوسط الحسابي للموارد البشرية ككل (r,77) وبدرجة تقدير (كبيرة).

وقد تعزى هذه النتيجة حسب تقديرات عينة الدراسة إلى الدور الذي يقوم به مدير المدرسة في تحقيق تعليم فعال للطلبة، من خلال ممارسـة

مدير المدرسة كمشرف مُقيم دوره الإداري في تحسين العملية التعليمياة. وهذا ما دلت عليه الفقرات الأولى من المجال.

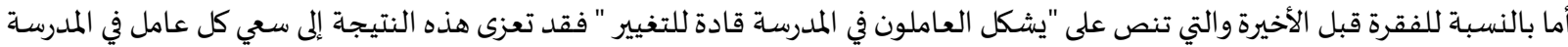
على الالتزام بدوره والقيام بواجباه، بهدف حفظ استمراريته في المؤسسة، أي الكل يسعى إلى حفظ دوره في مجال عمله، وخاصة بأن العمل في المؤسسة

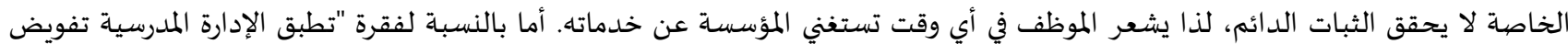
السلطات والصلاحيات بين العاملين" والتي جاءت بدرجة متوسطة، قد تعزى إلى أن الإشراف المباشر من قبل الإدارة، وعدم تحمل الإدارة إلى أي عبء مادي من تفويض الصلاحيات، فهدف المدارس الخاصة هو الربح، وتفويض الصلاحيات أحياناً يكبدها خسارة مالية، لذا فإنها تركز على الإشراف بنفسها على كل مستلزمات المدرسة وبشكل مستمر مون. وتختلف نتيجة هذا المجال مع ما أشار إليه المعيار العاشر كما ورد عن وزارة التربية والتعليم الأردنية لعام (10 ــ)، والمتمثلة بالموارد البشرية والذي يعني العناصر البشرية ذات المسؤوليات القيادية، والتي تحمل مؤهلات تخصصية مالية مالية. وتتفق هذه النتيجة مع نتيجة دراسة موسز ودافيد وستيفن (Moses , David and (Stephen, 2006) ، ودراسة ذياب والحاج وكيالي (Y . . ب) ،

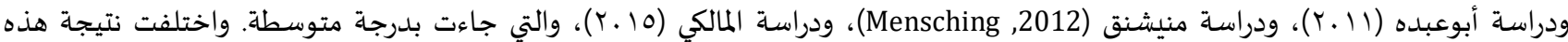

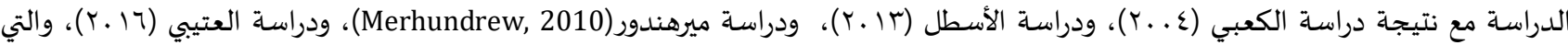
جاءت بدرجة كبيرة في تطبيق معايير الاعتماد في المدارس التربوية الخاصة دراسة. المجال السـادس: المجتمع المحلي تم حساب المتوسطات الحسابية والانحرافات المعيارية لفقرات مجال(المجتمع المحلي) حول تطبيق معايير الاعتماد في مدارس التعليم الخاص في الأردن من وجهة نظر القيادات التربوية في الأردن، مع مراعاة ترتيب الفقرات ضمن بعدها تنازليًا وفقًا لأوساطها الحسابية، كما في الجدول (9).

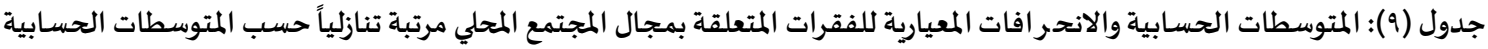

\begin{tabular}{|c|c|c|c|c|c|}
\hline 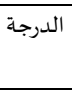 & الانحراف المعياري & المسابي & 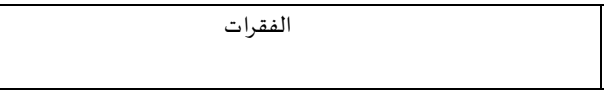 & 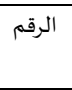 & 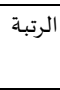 \\
\hline 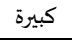 & זוד & $\varepsilon, .1$ & | يساعد التواصل بين المدرسة والمجتمع المحلي في تحسين تحصيل الطلبة & r & 1 \\
\hline كبيرة & $\cdot, 71$ & T,VT & | تلبي الخدمات التي تقدمها المدرسة حاجات حقيقية للمجتمع المحلي. & 7 & r \\
\hline كبيرة & $\cdot, \uparrow$. & $r, 0 \varepsilon$ & يوفر نظام الاتصال معلومات حديثة للآباء عن المستوى السلوكي لأبنائهم. & 1 & $r$ \\
\hline كبيرة & $\cdot, 79$ & $r, \varepsilon$. & |تتم عملية مشاركة المجتمع المحلي بناءً على الوعي بأهمية الشراكة & $\circ$ & $\varepsilon$ \\
\hline 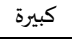 &., 07 & $r, 17$ & | يسهم المجتمع المحلي في حل مشكلات المدرسة المادية والفنية & r & $\circ$ \\
\hline 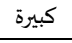 & $\cdot, \wedge 1$ & $r, V \varepsilon$ & |تساعد مشاركة المجتمع المحلي في تقديم المساعدة المطلوبة لبطيئي التعلم & $\varepsilon$ & 1 \\
\hline 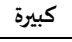 & . ह ₹r & $r, \varepsilon \varepsilon$ & المجتمع المحلي & & \\
\hline
\end{tabular}

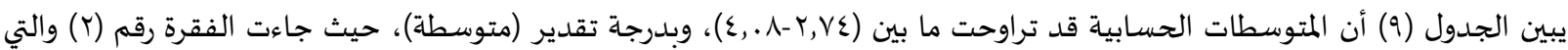
تنص على "يساعد التواصل بين المدرسة والمجتمع المحلي في تحسين تحصيل الطلبة" في المرتبة الأولى وبمتوسط حسابي بلغ (م..,ع)، وبدرجة تقدير

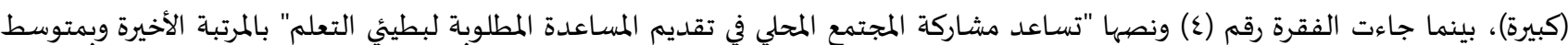

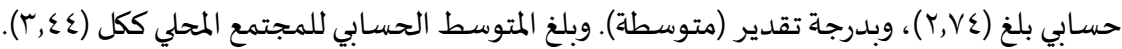

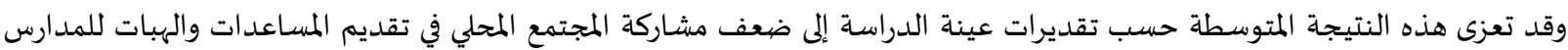
الخاصة على أساس أها مؤسسات ربحية، وبيان للمجتمع المحلي بأن المدارس الخاصة من المفترض أن تقدم هي جزء من أرباحها لمساعدة الطلبة ذوي الاحتياجات الخاصة، وذوي الدخل المحدود. أما بالنسبة للفقرة (1) والتي تنص على " يساعد التواصل بين المدرسة والمجتمع المحلي في تحسين تحصيل الطلبة "، والتي جاءت بدرجة كبيرة، فقد تعزى إلى أهمية دور تفعيل التواصل بين المدرسة والمجتمع المحلي في تحسين تحصيل الطلبة، من خلال اطلاع أولياء الأمور على احتياجات أبنائهم

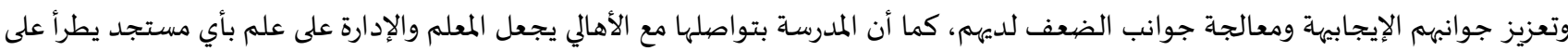
حالة الطالب قد تكون صحية، تحصيلية، نفسية، وغيرها من الأمور، من أجل تمكههم من تقديم المساعدة المناسبة للطالب، فالتواصل بين الأهل والمدرسة يشكل جانب إيجابي يعود بالنفع على الطالب. 
أما بالنسبة للفقرة (Y) والتي تنص على" تلبي الخدمات التي تقدمها المدرسة حاجات حقيقية للمجتمع المحلي." فقد جاءت درجة كبيرة، وقد

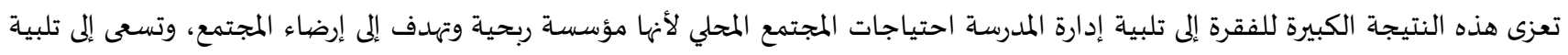
إحتياجاتهم،لضمان التنافسية، والجودة والاستمرارية، التي تحققها من خلال جودة مخرجاتها التعليمياة.

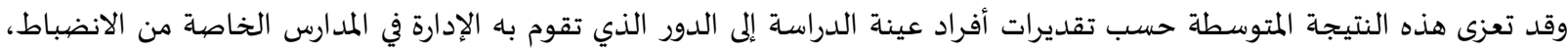

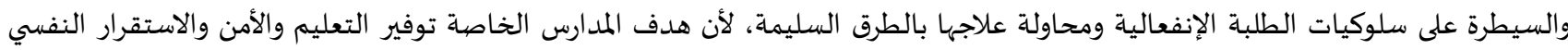

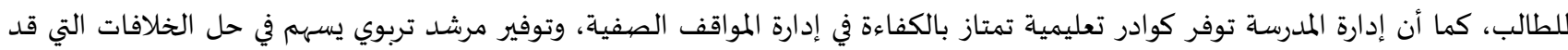

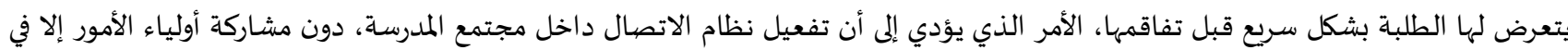

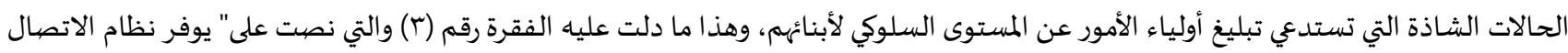
معلومات حديثة للآباء عن المستوى السلوكي لأبنائهم. ". أما بالنسبة للفقرة الأخيرة التي جاءت بدرئاء باءة متوسطة والتي نصت على" تساعد مشاركة المجتمع المحلي في تقديم المساعدة المطلوبة لبطيئي

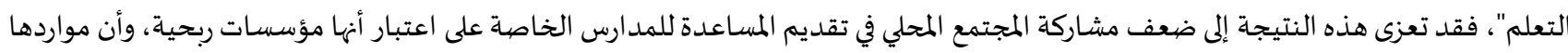
المالية كافية تقديم الخدمات اللازمة للطلبة، حيث أن الأهالي يدفعوا مبالغ مقابل تعليم أبنائهم، وبالمقابل يتطلب من إدارة المدرسة تقديم الخدمات للطلبة حسب احتياجاتهم. وبما أن معظم مؤسسـات التعليم الخاص تدار على أساس تجاري، فهي لا تتلقى أمولاً حكومية، وتعتمد بصفة أساسية على الرسوم المستوفاة

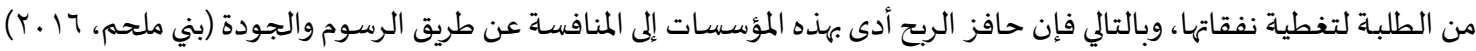

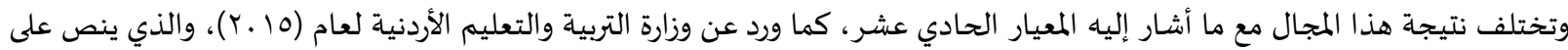

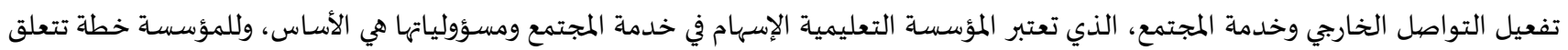

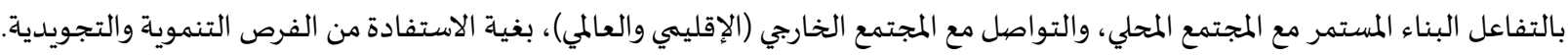

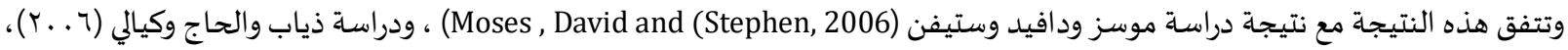

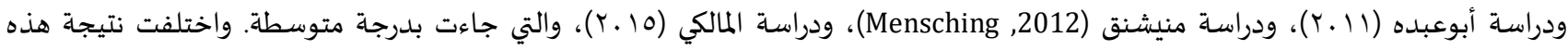

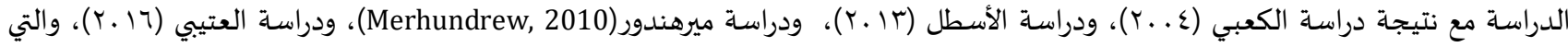
جاءت بدرجة تقدير كبيرة في تطبيق معايير الاعتماد في المدارس التربوية الخاصية. ودرسة

مناقشـة النتائج المتعلقة بالسؤال الثاني: هل توجد فروق ذات دلالة إحصيائية عند مستوى الدلالة (0.05 م) في تقديرات أفراد عينة الدراسـة حول درجة تطبيق معايير الاعتماد في مدارس التعليم الخاص في الأردن تعزى للمتغيرات: (الجنس، والنظام، والخبرة، والمؤهل العلمي) ؟

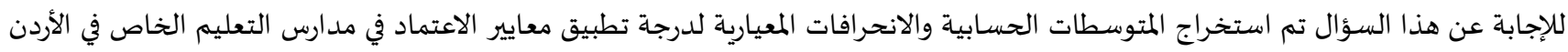

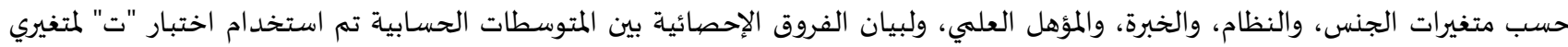

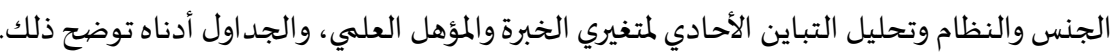

أولاً: النظام

للإجابة عن هذا متغير النظام تم استخراج المتوسطات الحسابية والانحرافات المعيارية المعيارية واختبار "ت" لأثر النظام على درجة تطبيق معايير الاعتماد في مد ارس التعليم الخاص في الأردن.

جدول ( ـ (): المتوسطات الحسابية والانحر افات المعيارية واختبار"ت" لأثر النظام على درجة تطبيق معايير الاعتماد في مدارس التعليم الخاص في الأردن

\begin{tabular}{|c|c|c|c|c|c|c|c|}
\hline الدلالة الإحصائية & درجات الحرية & "تيمة & المعياري & المسابي & العدد & النظام & \\
\hline.,$\ldots$ & $r \varepsilon \wedge$ & $\varepsilon, V)$. & 促, & $r, 91$ & $r \cdot \Lambda$ & أردني & \multirow[t]{2}{*}{ شؤون الطلبة } \\
\hline & & & . ros & $\varepsilon, T_{T}$ & $\varepsilon r$ & أجنبي & \\
\hline$\cdot, \ldots$ & $r \leqslant \wedge$ & $0,01 .-$ &., $0 Y 1$ & $r, v i$ & $r \cdot \Lambda$ & أردني & \multirow[t]{2}{*}{ التعلم والتعليم } \\
\hline & & & . & $\varepsilon, 11$ & $\varepsilon r$ & أجنبي & \\
\hline .,. & $r \varepsilon \wedge$ & $r, 0 . \varepsilon-$ & . rTV & $r, 7 \varepsilon$ & $r \cdot \Lambda$ & أردني & \multirow[t]{2}{*}{ المنهاج } \\
\hline & & &., 100 & $r, v q$ & $\varepsilon r$ & أجنبي & \\
\hline${ }^{\prime}, \ldots$ & $r \varepsilon \wedge$ & $0, \varepsilon 9 .-$ & ., & $r, \uparrow$. & $r \cdot \Lambda$ & أردني & \multirow[t]{2}{*}{ الموارد البشرية } \\
\hline & & & ., $\leq \leqslant \vee$ & $\varepsilon, \ldots$ & $\varepsilon r$ & أجنبي & \\
\hline$\cdot, r .1$ & $T \Sigma \Lambda$ & $1,$. ro- & זוז, & $r, \varepsilon r$ & $r \cdot \Lambda$ & أردني & \multirow[t]{2}{*}{ المجتمع المحلي } \\
\hline & & & . & $\Gamma, 0$. & $\varepsilon r$ & أجنبي & \\
\hline
\end{tabular}




\begin{tabular}{|c|c|c|c|c|c|c|c|}
\hline$\ldots 1$ & $r \varepsilon \wedge$ & r,TAl- &.,$\leq 9$. & $r, 99$ & T.1 & أردني & \multirow{2}{*}{ البنية التحتية } \\
\hline & & & .,01T & $\varepsilon, Y$ & $\varepsilon r$ & أجنبي & \\
\hline \multirow[t]{2}{*}{,$\ldots$} & $r \varepsilon \wedge$ & $\varepsilon, \Lambda) \mid$ &.,$r \leqslant 7$ & $r, \mathrm{rl}$ & T.1 & أردني & \multirow[t]{2}{*}{ معايير الاعتماد } \\
\hline & & & . TVV & $r, 91$ & $\varepsilon r$ & أجنبي & \\
\hline
\end{tabular}

يتبين من الجدول (. () وجود فروق ذات دلالة إحصائية (a=05) تعزى لأثر النظام في جميع المجالات، وفي الدرجة الكلية باستثناء مجال المجتمع المحلي وجاءت الفروق لصالح النظام الأجنبي.

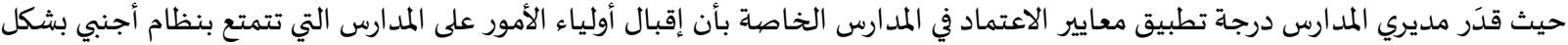

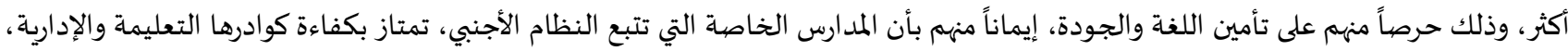

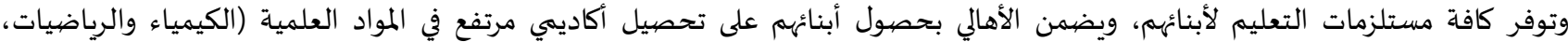

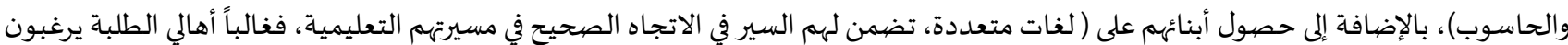
في تعليم أبنائهم مستقبلاً في كليات الطب والهنالدساة، وهذه الطلبات تتطلب تحصيل علمي مرتفع ومهارة في اللغة الأجنبية.

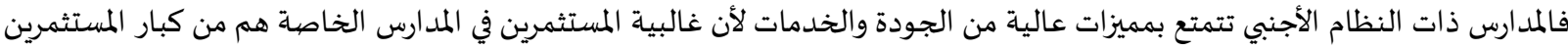

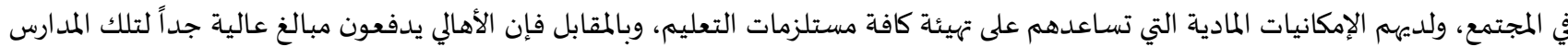

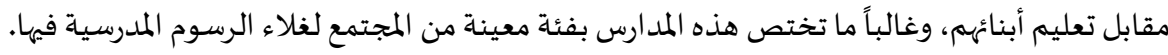
ثانياً: الجنس للإجابة عن هذا متغير الجنس تم استخراج المتوسطات الحسابية والانحرافات المعيارية المعيارية واختبار "ت" لأثر النظام على درجة تطبيق معايير الاعتماد في مدارس التعليم الخاص في الأردن الناسن

جدول (1): المتوسطات الحسابية والانحر افات المعيارية واختبار"ت" لأثر الجنس على درجة تطبيق معايير الاعتماد في مدارس التعليم الخاص في الأردن

\begin{tabular}{|c|c|c|c|c|c|c|c|}
\hline الإحصائية & درجات الحرية & "قيمة & الالنحراف & المتوسط الحسابي & العدد & الجنس & \\
\hline \multirow[t]{2}{*}{$\cdot, \wedge \varepsilon \varepsilon$} & $r \varepsilon \Lambda$ &., $19 V$ & . & $\varepsilon, .0$ & $r$. & ذكر & \multirow[t]{2}{*}{ شؤون الطلبة } \\
\hline & & & ., $\leq \leqslant \leq$ & $\varepsilon, . \varepsilon$ & rr. & أنثى & \\
\hline \multirow[t]{2}{*}{.,$\{07$} & 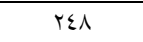 &.,$V \leqslant V-$ &., 019 & $r, V Y$ & $r$. & ذكر & \multirow[t]{2}{*}{ التعلم والتعليم } \\
\hline & & & .,OTr & $r, v q$ & Tr. & أنثى & \\
\hline \multirow[t]{2}{*}{., $17 \varepsilon$} & $T \Sigma \Lambda$ &.,$I V Y-$ & . & $r, 77$ & $r$. & ذكر & \multirow[t]{2}{*}{ المنهاج } \\
\hline & & & ג & r,TV & Tr. & أنثى & \\
\hline \multirow[t]{2}{*}{.,.$r \varepsilon$} & $r \Sigma \Lambda$ & r,וTr & .,$\varepsilon Y$. & $r, \lambda r$ & $r$. & ذكر & \multirow[t]{2}{*}{ الموارد البشرية } \\
\hline & & & ., $\{7 \uparrow$ & $r, 7 \varepsilon$ & rr. & أنثى & \\
\hline \multirow[t]{2}{*}{.,$Y \backslash 1$} & $r \leqslant \Lambda$ & 1, ros-- & . & r, ro & $r$. & ذكر & \multirow[t]{2}{*}{ المجتمع المحلي } \\
\hline & & & . & $r, \leqslant 0$ & rr. & أنثى & \\
\hline \multirow[t]{2}{*}{., 7.9} & $r \varepsilon \wedge$ &., 111 &., 009 & $\varepsilon, \cdot r$ & $r$. & ذكر & \multirow[t]{2}{*}{ البنية التحتية } \\
\hline & & & ., & $\varepsilon, . Y$ & rr. & أنثى & \\
\hline \multirow[t]{2}{*}{., 917} & $r \sum \Lambda$ &., $.1 \mathrm{~V}-$ & . זNT & $r, v 7$ & $r$. & ذكر & \multirow[t]{2}{*}{ معايير الاعتماد } \\
\hline & & &.,$r \leqslant v$ & $r, v 7$ & Tr. & أنثى & \\
\hline
\end{tabular}

يتبين من الجدول (11) عدم وجود فروق ذات دلالة إحصائية (1)=0.05) تعزى لأثر الجنس في جميع المجالات وفي الدرجة الكلية باستثناء

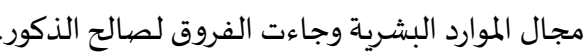
حيث قدَر مديري المدارس درجة تطبيق معايير الاعتماد في المدارس الخاصة بنفس الطريقة أي لم تظهر فروق ذائرات ذات دلالة إحصائية بين

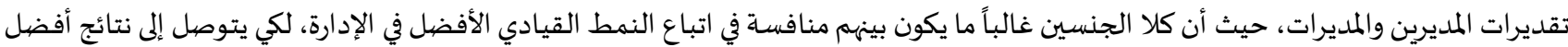
في تقديم الخدمات والبرامج التعليمية والأنشطة اللاصفية للطلبة من اكتساب ود الأهالي وتعزيز الاتصال والتواصل الماتل من قبل الأهالي في تدريس أبنائهم في كما أن كلا الجنسين يشترط أن يمتلكوا نفس الدورات التدريبية والأنشطة التربوية المساندة التي تقدم لهم الدعم والتعزيز في التعامل مع مختلف فئات الطلبة كل حسب ميولهم واحتياجاتهم التعليمية كشرط للإلتحاقهم بالتعين بالمدارس الخاصية، لكي يتمكنوا من تقديم المساعدة للطلبة التهات والمعلمين حسب احتياجاتهم الأكاديمية، ومن أجل تقديم التوعية والتثقيف لأسر الطلبة، عن اتجاهات وميول أبنائهم ومستواهم الأكاديمي، والمجال 
الذي من الممكن أن يكونوا مبدعين فياه عند تصنيف أبنائهم في المرحلة التعليمية المتقدمة(علمي، أدبي، مهن)، ومن جانب آخر لكي يستطيع المدير من

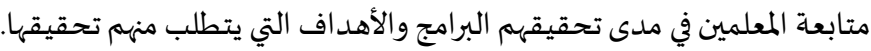
وقد تعزى هذه النتيجة إلى أن كلاهما تطبق عليهم الإجراءات والقوانين الملقاة عليهم من وزارة التربية والتعليم بشأن مختلف فئات الطلبة في

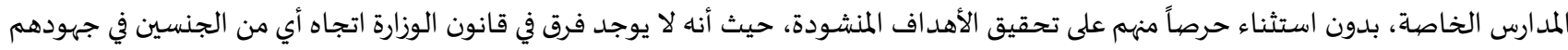
وقراراتهم أو تبادل الخبرات والمعلومات. وأن الظروف التي يعيشها المديرين من كلا الجنسين هي واحدة في مجتمع واحد أي أفكار المحيطة بهم أفكار مشتركة، ومشكلات مشتركه يعاني

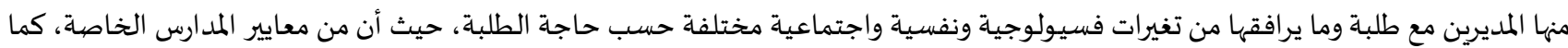
ورد عن وزارة التربية والتعليم لعام (10 ـ ب) والتي تمثل المعيار الثاني عشر الذي تضمن الأخلاقيات الملزمة، والتي تنص على أن تعتبر المؤسسـة مبدأ

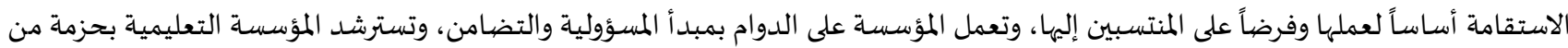

القيم الرفيعة في جميع ممارساتها. جاءت بشكل عام لمن يستطيع أن يحقق القدرة على تطوير العملية التربوية.

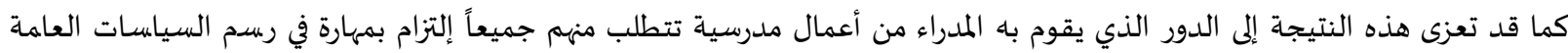

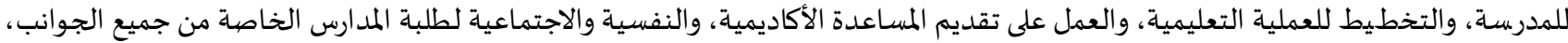

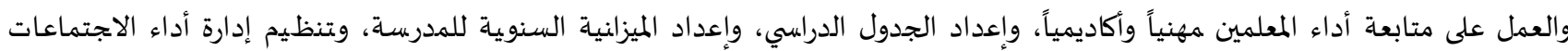
بالمعلمين، وأسر الطلبة، وتوزيع الأعمال والمسؤوليات على المعلمين والعاملين، وإجراء الدراسات فيما يختص بشؤون المدرسسة ومتطلباتها.

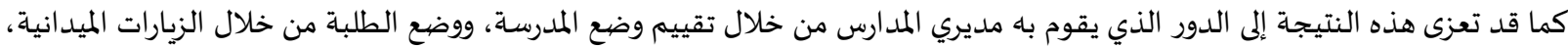

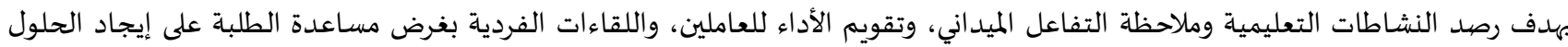
التربوية المناسبة وتحفيزهم، واللقاءات الجماعية بغرض التشاور مع الزملاء لتحقيق التكامل بين جهودهم، والنشرات التربوية بغرض نقل واءل الخبرات

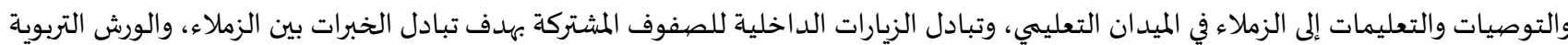
داخل المدرسة بهدف تنمية روح التعاون بين الزملاء، وإعداد قيادات تربوية قادرة على التجديد والابتكار.

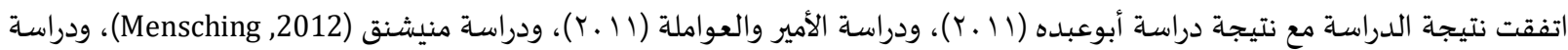

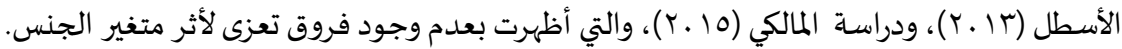

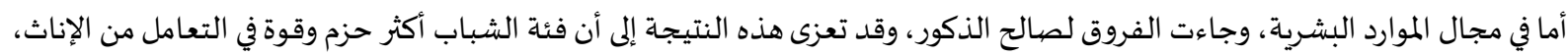

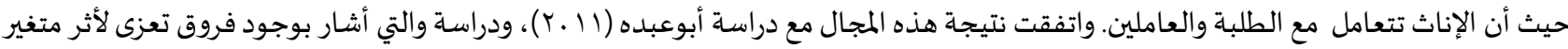
الجنس.

ثالثاً: المؤهل العلهي للإجابة عن هذا متغير (المؤهل العلمي) تم استخراج المتوسطات الحسابية والانحرافات المعيارية المعيارية واختبار التباين الأحادي لأثر النظام على درجة تطبيق معايير الاعتماد في مدارس التعليم الخاص في الأردن

جدول (r ا): المتوسطات الحسابية والانحر افات المعيارية لدرجة تطبيق معايير الاعتماد في مدارس التعليم الخاص في الأردن حسب متغير المؤهل العلمي

\begin{tabular}{|c|c|c|c|c|}
\hline الانحراف المعياري & المتوسط الحسابي & العدد & الفئات & \\
\hline דזוז, & r,AY & $0 \leqslant$ & بكالوريوس & شؤون الطلبة \\
\hline . & $\varepsilon, . \varepsilon$ & $1 \leqslant V$ & ماجستير & \\
\hline .,$\leq \leqslant V$ & $\varepsilon, T V$ & $\sum 9$ & دكتوراه & \\
\hline ., $\leqslant \leqslant 1$ & $\varepsilon, . \varepsilon$ & ro. & المجموع & \\
\hline., 011 & $r, 07$ & $0 \varepsilon$ & بكالوريوس & التعلم والتعليم \\
\hline.,$\varepsilon V V$ & r,vq & $1 \leqslant V$ & ماجستير & \\
\hline., orl & $\varepsilon, \cdot r$ & $\varepsilon 9$ & دكتوراه & \\
\hline ., OrI & $r, \mathrm{vA}$ & ro. & المجموع & \\
\hline$\cdot, \varepsilon \cdot Y$ & $r, v r$ & $0 \varepsilon$ & بكالوريوس & المنهاج \\
\hline . TrA & $r, 70$ & $1 \leqslant V$ & ماجستير & \\
\hline.,$r \leqslant V$ & $r, 70$ & $\varepsilon 9$ & دكتوراه & \\
\hline., roo & $r, 7 \mathrm{~V}$ & ro. & المجموع & \\
\hline . & $r, 77$ & $0 \varepsilon$ & بكالوريوس & الموارد البشرية \\
\hline.,$\leqslant \vee q$ & $r, \pi r$ & $1 \leqslant V$ & ماجستير & \\
\hline 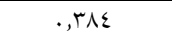 & $r, \Lambda$. & $\varepsilon 9$ & دكتوراه & \\
\hline
\end{tabular}




\begin{tabular}{|c|c|c|c|c|}
\hline 作, $\{777$ & $r, 77$ & ro. & المجموع & \\
\hline.,$r \leqslant r$ & $r, \xi 1$ & $0 \varepsilon$ & بكالوريوس & المجتمع المحلي \\
\hline 快 & $r, \varepsilon \varepsilon$ & $1 \leqslant V$ & ماجستير & \\
\hline ., $\{\wedge Y$ & $r, \sum \Lambda$ & $\varepsilon 9$ & دكتوراه & \\
\hline$\cdot, \sum 17$ & $r, \varepsilon \varepsilon$ & ro. & المجموع & \\
\hline .094 & $r, q r$ & $0 \varepsilon$ & بكالوريوس & البنية التحتية \\
\hline .,EVT & $r, 91$ & $1 \leqslant V$ & ماجستير & \\
\hline . ז人Т & $\varepsilon, r V$ & $\varepsilon 9$ & دكتوراه & \\
\hline., $0 .$. & $\varepsilon, \cdot r$ & ro. & المجموع & \\
\hline . זTO & $r, 7 v$ & $0 \varepsilon$ & بكالوريوس & معايير الاعتماد \\
\hline.,$r \leqslant r$ & $r, v \varepsilon$ & $1 \leqslant V$ & ماجستير & \\
\hline ., ro7 & $r, q$. & $\varepsilon 9$ & دكتوراه & \\
\hline .,rol & $r, v\urcorner$ & ro. & المجموع & \\
\hline
\end{tabular}

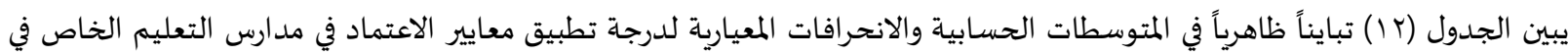

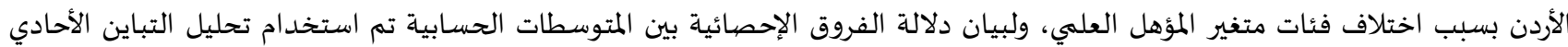

جدول (rا): تحليل التباين الأحادي لأثر المؤهل العلمي على درجة تطبيق معايير الاعتماد في مدارس التعليم الخاص في الأردن

\begin{tabular}{|c|c|c|c|c|c|c|}
\hline الإحصائية الدلالة & قيمة ف & متوسط المربعات & درجات الحرية & مجموع المربعات & المصدر & \\
\hline \multirow[t]{3}{*}{.,$\ldots$} & $10, \mathrm{rHA}$ & $r, 77$. & r & 0,419 & بين المجموعات & \multirow[t]{3}{*}{ شؤون الطلبة } \\
\hline & &., 180 & $r \varepsilon V$ & $\varepsilon r, 11 r$ & داخل المجموعات & \\
\hline & & & $r \leq q$ & $\{\Lambda, \varepsilon r$ & الكلي & \\
\hline \multirow[t]{3}{*}{$\cdot, \ldots$} & $1 ., 7 r \varepsilon$ & r,VAr & r & $0,07 \mathrm{~V}$ & بين المجموعات & \multirow[t]{3}{*}{ التعلم والتعليم } \\
\hline & & . ITY & $T \varepsilon V$ & $7 \varepsilon, 7 \leqslant V$ & داخل المجموعات & \\
\hline & & & $r \leq q$ & V.,YIT & الكلي & \\
\hline \multirow[t]{3}{*}{$\cdot, r \cdot \Lambda$} & 1,1גr &., $1 \leqslant 9$ & r &., rqV & بين المجموعات & \multirow[t]{3}{*}{ المنهاج } \\
\hline & &., $1<9$ & $r \varepsilon V$ & $r, \ldots \Lambda$ & داخل المجموعات & \\
\hline & & & $r \leqslant q$ & $r 1, r .0$ & الكلي & \\
\hline \multirow[t]{3}{*}{., .87} & $r, T \cdot r$ &., 001 & $r$ & 1,117 & بين المجموعات & \multirow[t]{3}{*}{ الموارد البشرية } \\
\hline & &.,$Y \backslash \leq$ & $r \leq V$ & or,91. & داخل المجموعات & \\
\hline & & & $r \varepsilon q$ & $0\{, .97$ & الكلي & \\
\hline \multirow[t]{3}{*}{$\cdot, V Y T$} & .,THI &., .07 & r &., $11 \mathrm{r}$ & بين المجموعات & \multirow[t]{3}{*}{ المجتمع المحلي } \\
\hline & & $\cdot, 1 V \varepsilon$ & $r \varepsilon V$ & $\varepsilon r, .01$ & داخل المجموعات & \\
\hline & & & $r \leq q$ & $\varepsilon r, 17 r$ & الكلي & \\
\hline \multirow[t]{3}{*}{$\cdot, \ldots$} & A, I TO & 1,941 & r & $r, \wedge \leq 1$ & بين المجموعات & \multirow[t]{3}{*}{ البنية التحتية } \\
\hline & & . זrד & $T \varepsilon V$ & 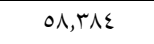 & داخل المجكوعات & \\
\hline & & & $r \varepsilon q$ & TY,YTO & الكلي & \\
\hline \multirow[t]{3}{*}{.,$\ldots r$} & $0,9 \cdot 7$ &., 799 & r & $1, r q V$ & بين المجموعات & \multirow[t]{3}{*}{ معايير الاعتماد } \\
\hline & &., 111 & $r \leq V$ & rq, riA & داخل المجموعات & \\
\hline & & & $r \varepsilon q$ & $r ., 710$ & الكلي & \\
\hline
\end{tabular}

يتبين من الجدول (rا) وجود فروق ذات دلالة إحصائية عند مستوى الدلالة (a=0.05) تعزى للمؤهل العلمي في جميع المجالات وفي الأداة ككل باستثناء المنهاج، والموارد البشرية، والمجتمع المحلي، ولبيان الفروق الزوجية المبادية الدالة إحصائيا بين المتوسطات الحسابية تم استخدام المقارنات البعدية بطريقة شيفيه كما هو مبين في الجدول (ع المارد ). 
جدول (ع ا): المقارنات البعدية بطريقة شيفيه لأثر المؤهل العلمي على درجة تطبيق معايير الاعتماد في مدارس التعليم الخاص في الأردن

\begin{tabular}{|c|c|c|c|c|c|}
\hline دكتوراه & ماجستير & بكالوريوس & المتوسط الحسابي & المؤهل العلهي & \\
\hline & & & $r, \Lambda T$ & بكالوريوس & \multirow[t]{3}{*}{ شؤون الطلبة } \\
\hline & & *.,TY & $\varepsilon, . \varepsilon$ & ماجستير & \\
\hline & $*, \pi T$ & $*_{.,}^{*}, 0$ & $\varepsilon, T V$ & دكتوراه & \\
\hline & & & $r, 07$ & بكالوريوس & \multirow[t]{3}{*}{ التعلم والتعليم } \\
\hline & & *.,rT & $r, v q$ & ماجستير & \\
\hline & $*_{.,}^{*}, \varepsilon$ & $*_{., \ell} \varepsilon \vee$ & $\varepsilon, . T$ & دكتوراه & \\
\hline & & & r,qr & بكالوريوس & \multirow[t]{3}{*}{ البنية التحتية } \\
\hline & &., .7 & $r, 91$ & ماجستير & \\
\hline & $*,$, , & *., ro & $\varepsilon, T V$ & دكتوراه & \\
\hline & & & $r, T V$ & بكالوريوس & \multirow[t]{3}{*}{ معايير الاعتماد } \\
\hline & &.,.$V$ & $r, V \varepsilon$ & ماجستير & \\
\hline & $* ., 17$ & *., rT & $r, q$. & دكتوراه & \\
\hline
\end{tabular}

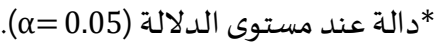

يتبين من الجدول (ع () الآتي:

وجود فروق ذات دلالة إحصائية (م=0.05) بين بكالوريوس من جهة وكل من ماجستير، ودكتوراه من جهة أخرى، وجاءت الفروق لصالح كل من

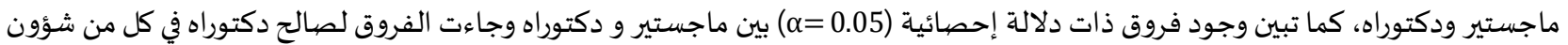
الطلبة، والتعلم والتعليم. وجود فروق ذات دلالة إحصائية (0.05) بين دكتوراه من جهة وكل من بكالوريوس، وماجستير من جهة أخرى وجاءت الفروق لصالح دكتوراه، في كل من البنية التحتية، ومعايير الاعتماد. وقد تعزى هذه النتيجة إلى الدور الذي يتمتع به أصحاب المؤهلات العلمية من الخبرة والدراية والخبرات من خلال اطلاعهم على خبرات متنوعة في مجال الدراسة في مرحلة الدكتوراه. كما تعزى هذه النتيجة إلى أن غالبية المدراء من أصحاب المؤهل العلمي (الدكتوراه) لديهم مخزون ثقافي وعلمي من العمل نحو التغيير والتطوير واتباع طرق ووسائل حديثه من أجل الحصول على طريقة مناسبة للتعامل مع الطلبة بمختلف فئاتهم في المدارس الخاصية، ومعلميهم، مع المحافظة على مئى

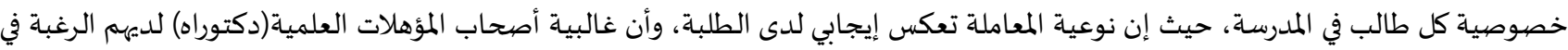

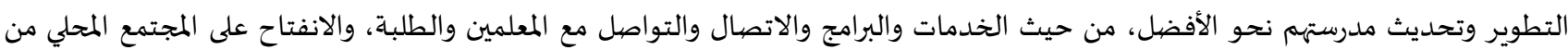
خلال بيانه لهم أهمية الدور الذي تقدمه المدرسة للطلبة من أجل الحصول على كفاءة وجودة في مخرجاتهم التعليمية. وقد تعزى هذه النتيجة حسب تقديرات أفراد عينة الدراسة بأن ارتفاع المؤهل العلمي للمدير يصبح أقدر على الحهي الحكم على ممارسات الآخرين من المجتمع والمعلمين، ولدياء معرفة واسعة عن عمل الإدارة واحتياجات الطلبة فها كل حسب حاجتاه، حيث إن ارتفاع المؤهل العلمي يزيد عند صاحبه

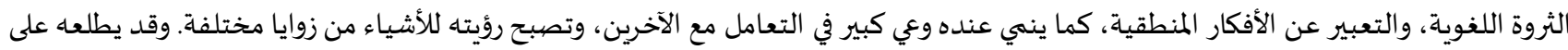
الكثير من خبرات وتجارب الكثير من المدراء نتيجة التحاور والتفاعل مع مختلف فئات المدراء من أماكن متنوعه، تكسب المدير سعة واسعة في التنوع في

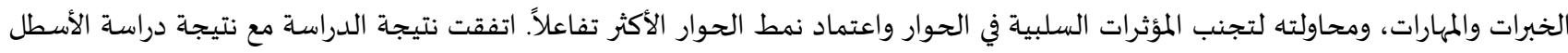

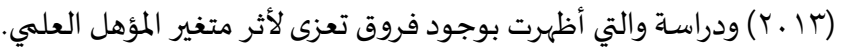
رابعاً: الخبرة جدول (10): المتوسطات الحسابية والانحر افات المعيارية لدرجة تطبيق معايير الاعتماد في مدارس التعليم الخاص في الأردن حسب متغير الخبرة

\begin{tabular}{|c|c|c|c|c|}
\hline الانحراف المعياري & المتوسط الحسابي & العدد & الفئات & المتغيرات \\
\hline .,$\leqslant 0 \leqslant$ & $\varepsilon, I T$ & rq & أقل أو يساوي ه سنوات & شؤون الطلبة \\
\hline ., \&ro & $\varepsilon, .9$ & IrT & أقل من • اسنوات & \\
\hline.,$\varepsilon r)$ & $r, 91$ & $\mathrm{vA}$ & أكثر من • ا سنوات & \\
\hline.,$\leq \leqslant 1$ & $\varepsilon, . \varepsilon$ & ro. & المجموع & \\
\hline., $0 \vee 9$ & $r, 7 \mathrm{~V}$ & rq & أقل أو يساوي ه سنوات & التعلم والتعليم \\
\hline., $01 Y$ & $r, \wedge \varepsilon$ & Tr & أقل من • اسنوات & \\
\hline ., ors & $r, v 7$ & $\mathrm{VA}$ & أكثر من · ا سنوات & \\
\hline., 0 Or & $r, \mathrm{VA}$ & ro. & المجموع & \\
\hline . TIV & $r, v\urcorner$ & $r q$ & أقل أو يساوي ه سنوات & المنهاج \\
\hline
\end{tabular}




\begin{tabular}{|c|c|c|c|c|}
\hline . TrI & $r, 7$. & Trt & أقل من · اسنوات & \\
\hline ., rr. & $r, v \varepsilon$ & vi & أكثر من · ا سنوات & \\
\hline ., roo & $r, 7 v$ & ro. & المجموع & \\
\hline$\cdot,\{0 \leqslant$ & $r, v$. & rq & أقل أو يساوي ه سنوات & الموارد البشرية \\
\hline •, $ะ 91$ & $r, 7 \Lambda$ & IrT & أقل من • ا سنوات & \\
\hline.,$\$ 10$ & $r, 7 r$ & $\mathrm{v} \wedge$ & أكثر من · ا سنوات & \\
\hline . $\{877$ & $r, 77$ & ro. & المجموع & \\
\hline.,$\{01$ & $r, o$. & $r 9$ & أقل أو يساوي ه سنوات & المجتمع المحلي \\
\hline$\cdot, \leq \varepsilon 1$ & $r, \varepsilon$. & irr & أقل من • ا سنوات & \\
\hline.,$r \varepsilon \wedge$ & $r, \varepsilon V$ & $v \wedge$ & أكثر من · ا سنوات & \\
\hline., 817 & $r, \varepsilon \varepsilon$ & ro. & المجموع & \\
\hline., $0 \ldots$ & $\varepsilon, 11$ & ra & أقل أو يساوي ه سنوات & البنية التحتية \\
\hline$\cdot, \varepsilon \mu$ & $\varepsilon, \cdot r$ & 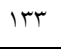 & أقل من • ا سنوات & \\
\hline., $0 \wedge \mathrm{r}$ & $r, 97$ & $\mathrm{VA}$ & أكثر من • ا سنوات & \\
\hline., $0 .$. & $\varepsilon, . r$ & ro. & المجموع & \\
\hline . & $r, \Lambda$. & $r q$ & أقل أو يساوي ه سنوات & معايير الاعتماد \\
\hline . ror & $r, v 7$ & $1 \pi r$ & أقل من • اسنوات & \\
\hline .,$r \varepsilon r$ & $r, v r$ & $\mathrm{v \Lambda}$ & أكثر من · ا سنوات & \\
\hline., rol & $r, v\urcorner$ & ro. & المجموع & \\
\hline
\end{tabular}

يبين الجدول (10) تبايناً ظاهرياً في المتوسطات الحسابية والانحرافات المعيارية لدرجة تطبيق معايير الاعتماد في مدارس التعليم الخاص في

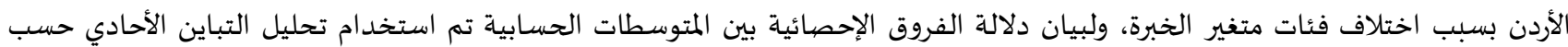

جدول (17): تحليل التباين الأحادي لأثر الخبرة على درجة تطبيق معايير الاعتماد في مدارس التعليم الخاص في الأردن

\begin{tabular}{|c|c|c|c|c|c|c|}
\hline الإحصائية الدلالة & قيمة ف & متوسط المربعات & درجات الحرية & مجموع المربعات & المصبدر & \\
\hline \multirow[t]{3}{*}{.,$\ldots 7$} & $0, Y \cdot r$ &., $9 \vee 9$ & r & 1,901 & بين المجموعات & \multirow[t]{3}{*}{ شؤون الطلبة } \\
\hline & &., $1 \wedge$ & $r \leq V$ & $\varepsilon 7, \varepsilon \vee \varepsilon$ & داخل المجموعات & \\
\hline & & & $r \leq q$ & $\{\Lambda, \varepsilon \Gamma$ & الكلي & \\
\hline \multirow{3}{*}{., 110} & $1, \vee \ldots$ & $\cdot, \varepsilon V V$ & r &., $90 \leqslant$ & بين المجموعات & \multirow[t]{3}{*}{ التعلم والتعليم } \\
\hline & &., $\mathrm{r \Lambda}$ & $r \varepsilon V$ & $79, Y 7$. & داخل المجموعات & \\
\hline & & & $r \leqslant q$ & $V \cdot, r \mid r$ & الكلي & \\
\hline \multirow[t]{3}{*}{.,$\ldots r$} & $0,9 r \mathrm{~T}$ & $\cdot, \mathrm{V} \backslash \mathrm{V}$ & r & $1, \varepsilon r_{0}$ & بين المجموعات & \multirow[t]{3}{*}{ المنهاج } \\
\hline & & $.|| Y \mid$ & $r \leq V$ & $r q, \wedge V 1$ & داخل المجموعات & \\
\hline & & & $r \leqslant q$ & $r, r .0$ & الكلي & \\
\hline \multirow[t]{3}{*}{., 711} & $\cdot,\{\wedge 1$ &., 1.0 & r & $\cdot, Y)$. & بين المجموعات & \multirow[t]{3}{*}{ الموارد البشرية } \\
\hline & &.,$Y \backslash \Lambda$ & $r \varepsilon V$ & or, , 117 & داخل المجموعات & \\
\hline & & & $r \leq q$ & $0\{, .97$ & الكلي & \\
\hline \multirow[t]{3}{*}{$\cdot, r \cdot v$} & $1,1 \wedge \mathrm{V}$ &.,$Y .0$ & r &.,$\varepsilon 11$ & بين المجموعات & \multirow[t]{3}{*}{ المجتمع المحلي } \\
\hline & &.,$I V T$ & $r \leq V$ & $\varepsilon r, V O r$ & داخل المجموعات & \\
\hline & & & $r \leq q$ & $\varepsilon r, 17 r$ & الكلي & \\
\hline \multirow[t]{3}{*}{.,.$V r$} & $r, 7 \leqslant 9$ & , tor & $r$ & $1, r \cdot 7$ & بين المجموعات & \multirow[t]{3}{*}{ البنية التحتية } \\
\hline & &.,$Y \leqslant V$ & $r \varepsilon V$ & $7 ., 919$ & داخل المجموعات & \\
\hline & & & $r \leqslant q$ & TY,YYO & الكلي & \\
\hline \multirow[t]{2}{*}{., $09 \varepsilon$} & .,OKr &., .70 & $r$ &., $1 \mathrm{rq}$ & بين المجموعات & \multirow[t]{3}{*}{ معايير الاعتماد } \\
\hline & &., $1 \mathrm{KT}$ & $r \leqslant V$ & $r \cdot, \varepsilon \wedge\rceil$ & داخل المجموعات & \\
\hline \multicolumn{4}{|c|}{$r \leqslant 9$} & $r ., 710$ & الكلي & \\
\hline
\end{tabular}




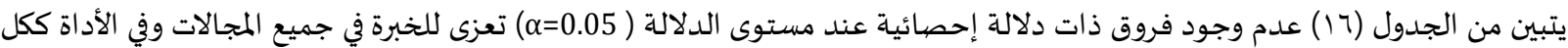
باستثناء مجالي شؤون الطلبة، والمنهاج، ولبيان الفروق الزوجية الدالة إحصائيا بين المتوسطات الحسابية تم استخدام المقارنات البعدية بطريقة

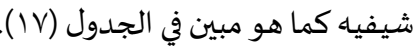

جدول (IV) : المقارنات البعدية بطريقة شيفيه لأثر الخبرة على مجالي شؤون الطلبة والمنهاج

\begin{tabular}{|c|c|c|c|c|c|}
\hline اكثرمن · 1 اكنوات & اكنر من ه ا سنوات اقل & ه سنوات فما & الحستابي & الخبرة & \\
\hline & & & $\varepsilon, 1 T$ & م سنوات فما دون & \multirow[t]{3}{*}{ شؤون الطلبة } \\
\hline & &.,$+r$ & $\varepsilon, .9$ & اكثر من ه - اقل من ـ اسنوات & \\
\hline & $*^{*}, 1 \curlywedge$ & $*,, Y$ & $r, 91$ & اكثر من · اسنوات & \\
\hline & & & $r, \mathrm{~V} 7$ & ه سنوات فما دون & \multirow[t]{3}{*}{ المنهاج } \\
\hline & & $*_{.,}^{*}, \mathrm{~V}$ & $r, \uparrow$. & اكثر من ه - اقل من ـ ا سنوات & \\
\hline & $* ., 1 \varepsilon$ &.,.$T$ & $r, v \varepsilon$ & اكثر من · اسنوات & \\
\hline
\end{tabular}

(مالة عند مستوى الدلالة (م=0.05).

يتبين من الجدول (IV) الاتي:

وجود فروق ذات دلالة إحصائية (م=0.05) بين اكثر من · ا سنوات من جهة وكل من ه سنوات فما دون، وأكثر من ه- اقل من • ا سنوات من جهاة

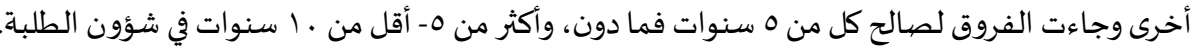

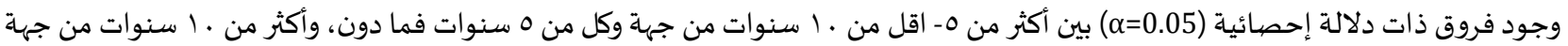

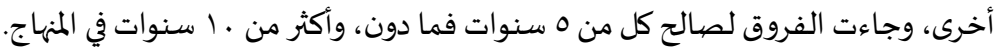

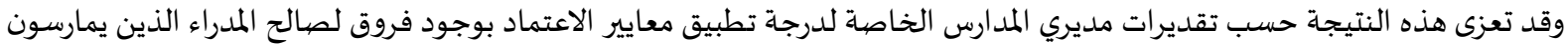

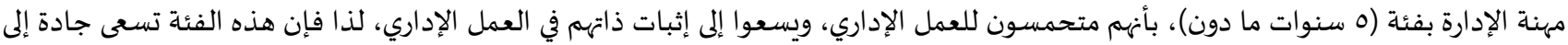

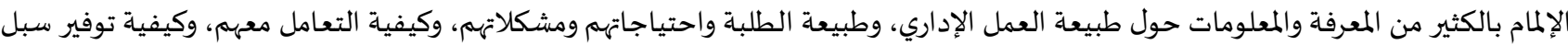

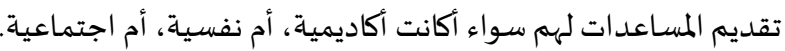
كما قد تعزى هذه النتيجة إلى الدور الذي يقوم به المديرون من تطوير وتحسين كفاياتهم الإدارية التي تساعدهم على التواصل مع مدراء

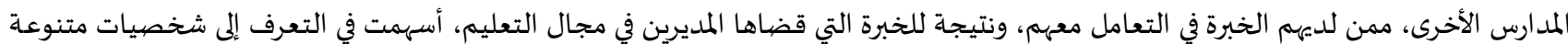

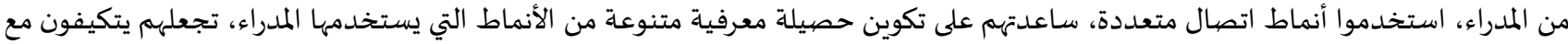

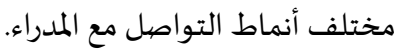
أما بالنسبة لتقديرات مديري المدارس التي جاءت لصالح خبرة الفئة (. (1) سنوات فأكثر، بأن المديرين لديهم الدراية والخبرة الإدارية التي

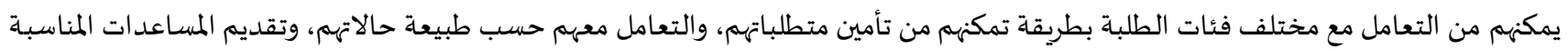
لهم حسب ظروفهم واحتياجاتهم الأكاديمية والنفسية. اتفقت نتيجة الدراسة مع نتيجة دراسة المالكي (10 ـ ب) والتي أشارت بوجود فروق تعزى لمتغير

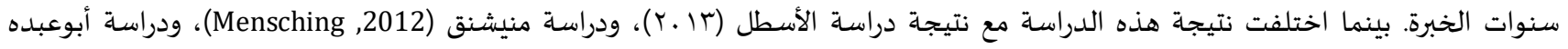
(1 (1) )، والتي أظهرت بعدم وجود فروق فردية بين متغيرات الدراسـة.

التوصيات:

بناء على نتائج الدراسـة توصي الباحثة بعدة توصيات أهمها: أن تسهم القيادات التربوية في المدارس الخاصة في تشخيص جوانب الضعف والقوة من المنهاج، وأن يتم تفعيل نظام حوسبة المنهاج من قبل المدارس الخاصية بشكل أكثر. أن يشكل العاملون في المدارس الخاصة قادة للتغيير، أن يتم تطبيق الإدارة المدرسية تفويض الصلاحيات بين العاملين. تفعيل مشاركة المدارس الخاصة مع الأهالي والمجتمع المحلي من خلال تعزيز برامجها التوعوية والإرشادية والتي تعزز دورها من خلال تعريف

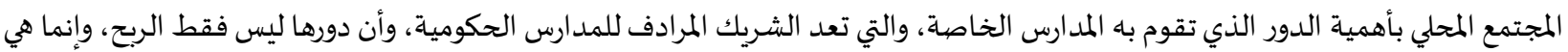
مؤسسة تربوية تعليمية قادرة على إخراج كفاءات ذات جودة عالية. ضـرورة قيام وزارة التربية والتعليم للمدارس الخاصة بعقد دورات تدريبيـة وورش عمل متخصصة بالتخطيط وفق معايير ضمان الجودة،

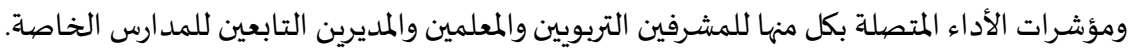
نقترح إجراء مزيد من الدراسـات مماثلة في مدارس التعليم الخاص خارج عمان العاصمة 


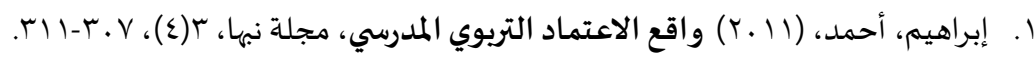

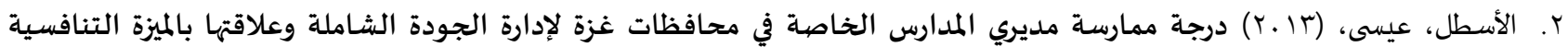

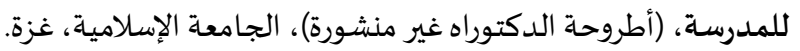

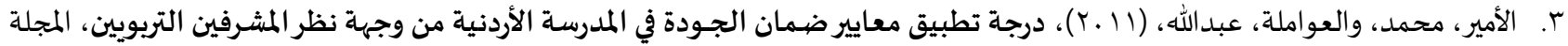

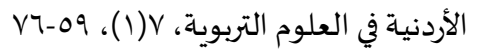

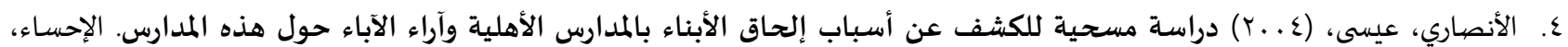
السعودية.

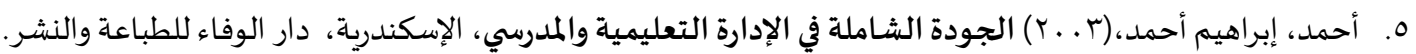

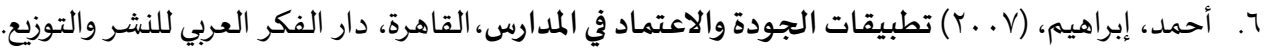

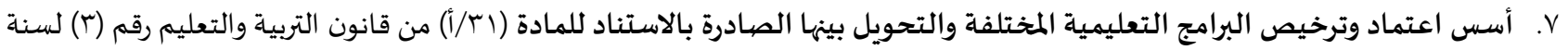

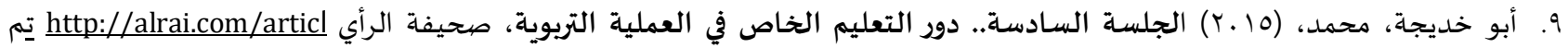

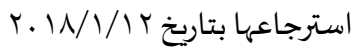

• ا. الخطيب، أحمد، والخطيب،رداح، (7 ـ ـ ب) إدارة الجودة الشـاملة: تطبيقات تربوية، الأردن، دار الكتاب الحديث. الـ الخطيب، سمير، (1 . . ب). إدارة الجودة الشاملة والأيزو، مدخل معاصبر. العراق، دار المرتضى للنشر والتوزيع.

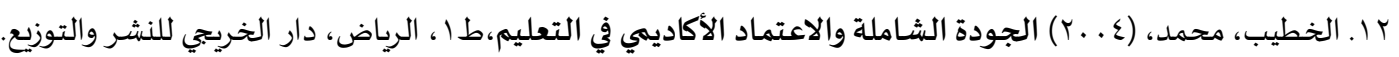

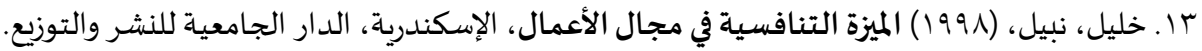

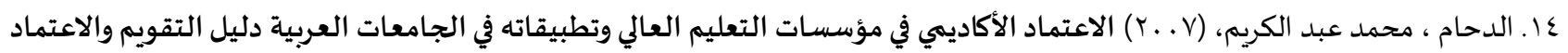

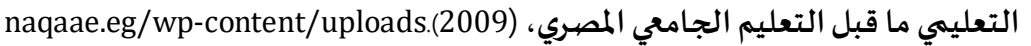

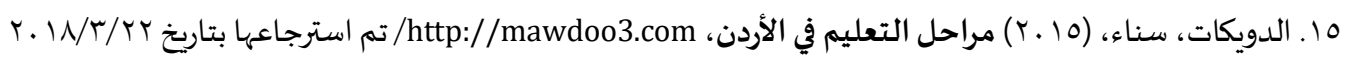

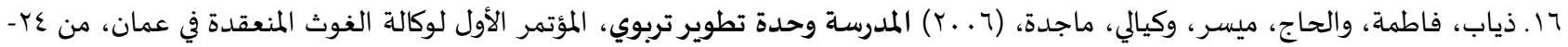
r. . T/乏/TV

IV

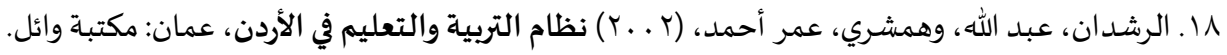

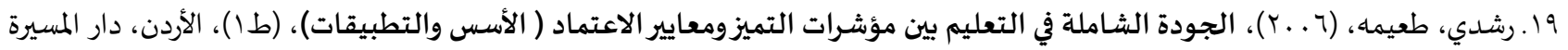
للنشر والتوزيع.

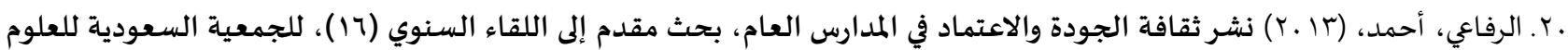

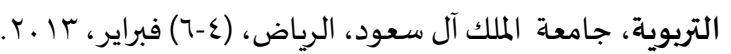

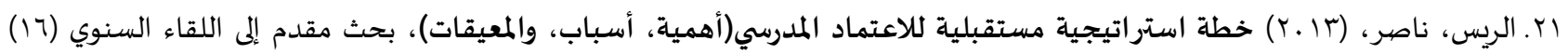

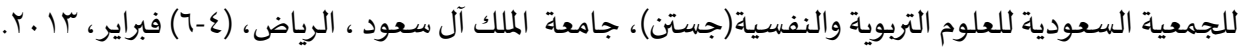

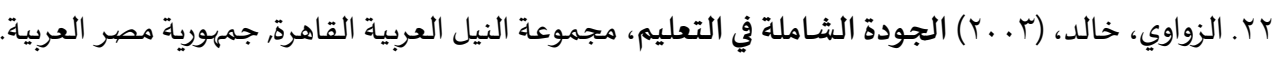

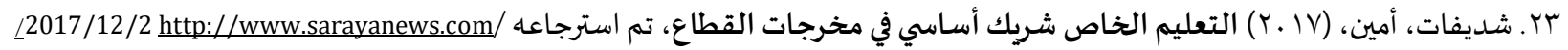

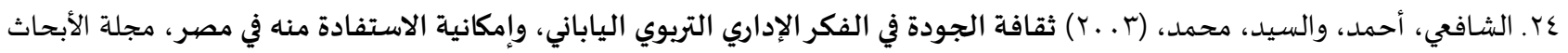

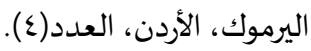

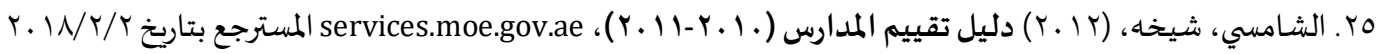

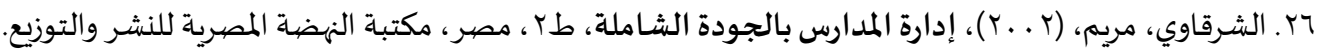

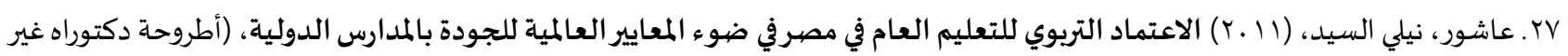

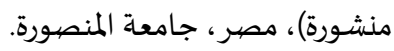




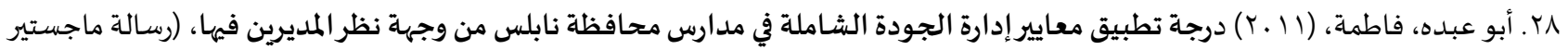
غير منشورة)، كلية التربية، جامعة النجاح الوطنية ، فلسطين.

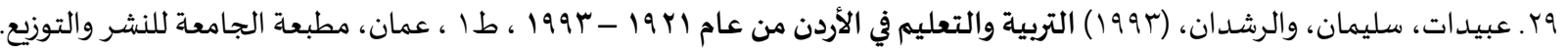

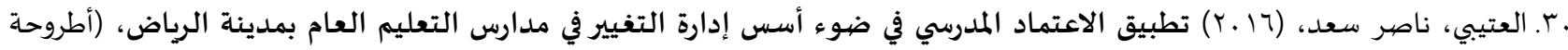

$$
\text { دكتوراه غير منشورة)، جامعة أم القرى، السعودية. }
$$

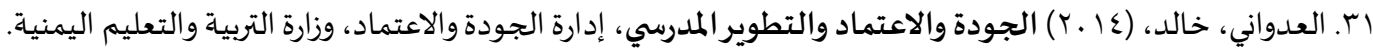

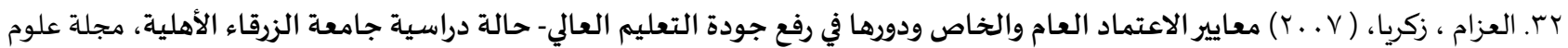

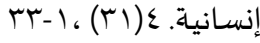

rr. عليمات، صالح، (r ا •r) إدارة الجودة الشاملة في المؤسسات التربوية، (التطبيق ومقترحات التطوير)، طا، عمان، الأردن، دار الشروق للنشر والتوزيع.

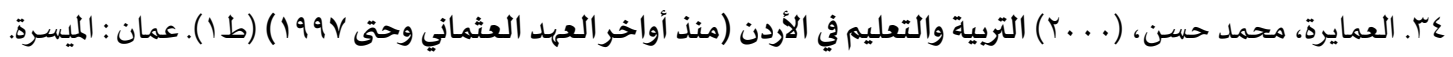

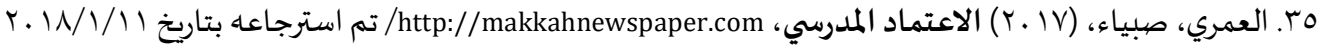

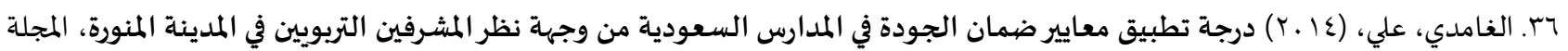

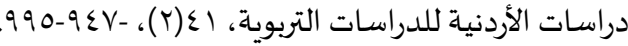

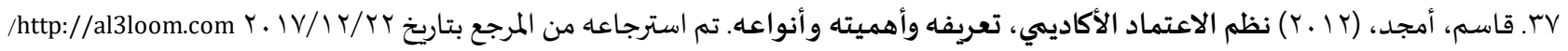

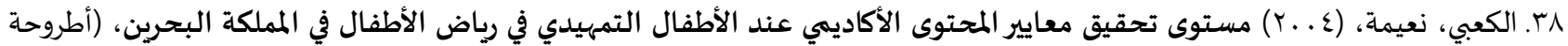
دكتوراه غير منشورة)، الجامعة الأردنية.

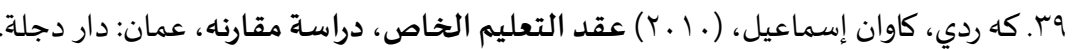

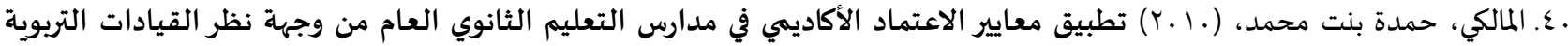

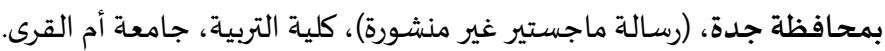

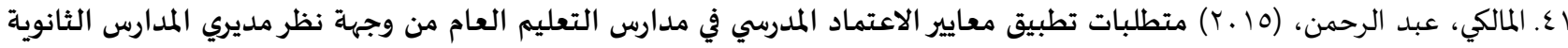

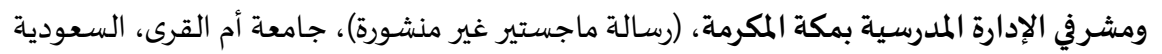

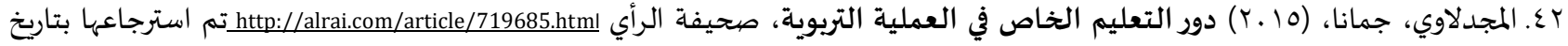
$r . \mid N / T / Y T$

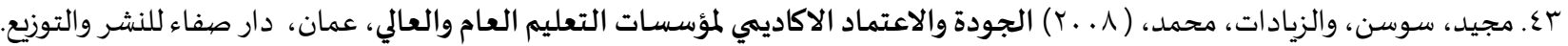

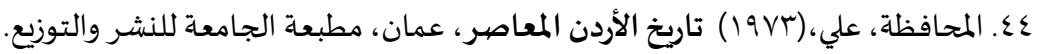

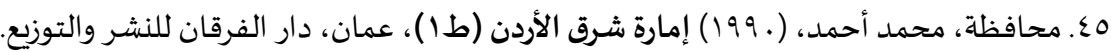

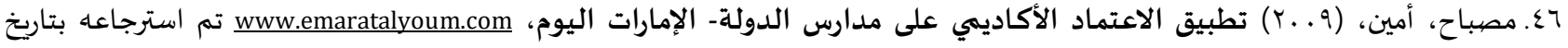
$r \cdot T N / T / Y r$

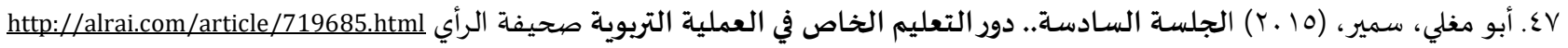
r. IN/M/I Tم استرجاعها بتاريخ

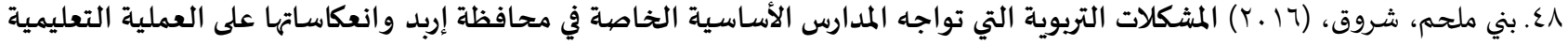
من وجهة نظر المعلمين وسبل التغلب عليها، (أطروحة دكتوراه غير منشورة)، كلية التربية، جامعة الئية اليرموك.

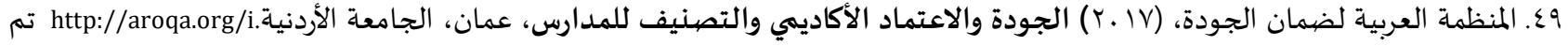

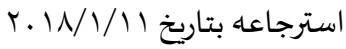

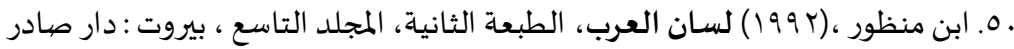

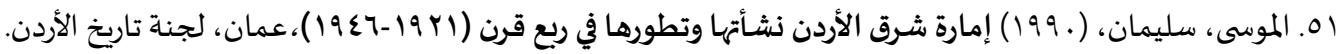

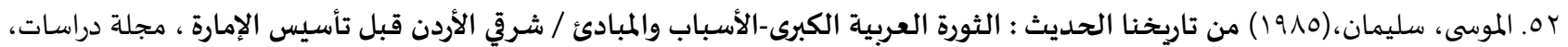

rurrerq ، (11) ro ناصر، إبراهيم، (r 1991) علم الاجتماع التربوي(ط ا))، عمان، دار الجيل للنشر والتوزيع. 
عه. النجار، عبد الوهاب، (V. . . الاعتماد الأكاديمي لمؤسسات إعداد المعلمين كوسيلة لضمان الجودة في مؤسسات التعليم العام، ورقة عمل

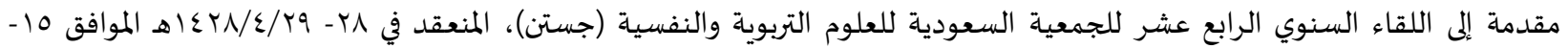

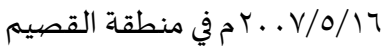

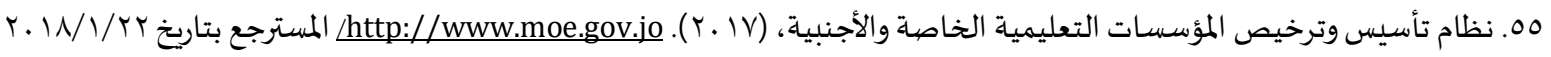

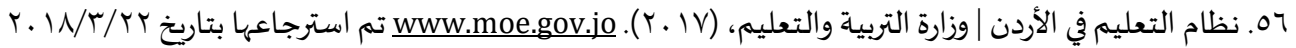

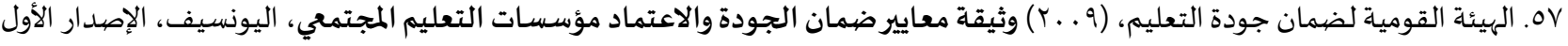

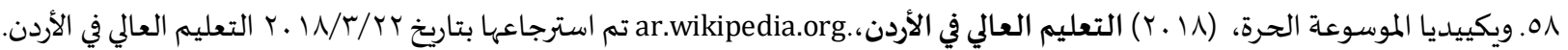

[1] Accreditation International, http://www.aiaccredits.org/Home.html

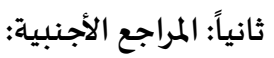

[2] Accreditation Standards for Dietetic Education Programs in Canada (2014), https://www.dietitians.ca/

[3] Barresi. j., Standards for Accreditation of Oklahoma Schools 2014-2015 (2017), http://www.sde.ok.gov

[4] Fairman. J., Peirce. B., \& Harris. W., High School Accreditation in Maine: Perceptions of Costs and Benefits, Center for Research and Evaluation, College of Education and Human Development, University of Maine, (2009).

[5] Gandal. M \& Vranek. J., sept. Standards: Here today, here tomorrow. Educational Leadership, 59 (1) (2001), 6-13.

[6] Harvey. L \& Stensaker. B., Quality culture: understandings, boundaries and linkages, European Journal of Education, 43(4) (2008), 427- 442, https://doi.org/10.1111/j.1465-3435.2008.00367.x

[7] Johansen. C., Jan. Total Quality management in a knowledge. management Journal of Documentation, 56 (1) (2010). 42-54 ,ERIC. E1608496.

[8] Joshua. C., Diversity and Social Justice in Teacher Education Accreditation Standards: 1995 to 2013. Submitted to the Graduate Faculty as partial fulfillment of the requirements for the Doctor of Philosophy Degree in Educational Sociology, (2015).

[9] Leithwood. K., Harris. A., \& Strauss. T., Leading school turnaround: How successful leaders transform lowperforming schools. San Francisco: Jossey-Bass, (2010).

[10] McBrien. L., \& Brandt. R., The language of learning: A guide to education terms. Alexandria, VA: Association for Supervision and Curriculum Development, (1997).

[11] Mensching. B., School Accreditation and Its Impact on Our Wels Schools. (Unpublished Master Thesis) Martin Luther Collage. Denmark, (2012).

[12] Merhundrew. B., Superintendent Perceptions of the Accreditation Process in the State of Mississippi. Pro Quest LLC. 789 East Eisenhower Parkway, PO Box 1346, Ann Arbor, MI 48106, (2010).

[13] Moses. N. David. W. \& Stephen. O., Total Quality Management in Secondary Schools in Kenya: Extent of Practice, Quality Assurance in Education. 14(4) (2006), 339- 362, https://doi.org/10.1108/09684880610703947

[14] National Council for Teacher Quality. (2014, September 1). About. Retrieved from .http://www.nctq.org/about/

[15] New Zealand Certificates for secondary schools » NZQA(2015), www.nzqa.govt.nz

[16] Pillsbury. SE., National Standards \& Quality Indicators Transition Toolkit forSystems Improvement, National Center on Secondary Education andTransition Institute on Community Integration (UCE), University of Minnesota, (2012).

[17] Special Education (2017), www.edb.gov.hk/en/edu-system/special/policy

[18] Wiggins. G., Standards, Not Standardization: Evoking Quality Student Work . Educational Leadership, 48(5) (1995).

[19] Williams. G. O., Identifying Principals'Practices That Affect Achievement And Accreditation Of Public Elementary, Middle, And High Schools In Virginia (Doctoral dissertation, Virginia Polytechnic Institute and State University, (2008). 


$$
\text { المجلة الدولية للدراسـات التربوية والنفسية }
$$

International Journal of Educational \& Psychological Studies (EPS)

Journal Homepage: https://www.refaad.com/views/EPSR/Home.aspx

www.refaad.com

ISSN: 2520-4149 (Online) 2520-4130 (Print)

\title{
Assessing the Degree of Applying Accreditation Standards at Private Educational
} Schools In Jordan

\author{
Amal Saleh Mahjoub Maharma \\ Graduate student- Jordan \\ Saadbanihani@hotmail.com
}

Received Date : $12 / 2 / 2020$

Accepted Date : 2/3/2020

DOI : https://doi.org/DOI:10.31559/EPS2020.7.3.3

\begin{abstract}
This study aimed to identify the degree of application of the accreditation Criteria in Private Education Schools in Jordan. The descriptive method was used. The Study Sample Consisted of (250) Managers. It was Chosen by Random Class method Among the Study Population of (612) In order to Achieve the Objectives of the Study. The Results of the Study Showed that the Estimates of the Sample Members of the study Sample Came to a great Extent in the fields of Degree of Application of the Accreditation Criteria in the Private Education Schools in Jordan. The Results Showed that there were Statistically Significant differences in the level of responses of the sample Members in the degree of Applying the Accreditation criteria in the Special education Schools in Jordan The Results are due to the Differences in Variables (system, gender, scientific qualification, and years of experience) on all fields of Study and the total Instrument. The Results Showed no differences due to the Effect of the gender Variable. (5) Years and below, and (10) years and more. Based on the results of the study, the Researcher Recommended the Necessity of Activating the Participation of the Management of private Schools with the people and the local by Enhancing their Awareness and guidance programs.
\end{abstract}

Keywords: Schools Private; Standards of Accreditation; Private education.

\section{References:}

[1] 'ashwr. Nyly Alsyd, Ala'tmad Altrbwy Llt'lym Al'eam Fy Msr Fy Dw' Alm'ayyr Al'almyh Lljwdh Balmdars Aldwlyh, (Atrwht Dktwrah Ghyr Mnshwrh), Msr, Jam't Almnswrh, (2011).

[2] Abw 'bdh. Fatmh, Drjt Ttbyq M'ayyr Edart Aljwdh Alshamlh Fy Mdars Mhafzt Nabls Mn Wjht Nzr Almdyryn Fyha, (Rsalt Majstyr Ghyr Mnshwrh), Klyt Altrbyh, Jam't Alnjah Alwtnyh, Flstyn, (2011).

[3] 'bydat. Slyman \& Alrshdan, Altrbyh Walt'lym Fy Alardn Mn 'am 1921 - 1993 , T1 , 'man, Mtb't Aljam'h Llnshr Waltwzy'.

[4] Al'dwany. Khald, Aljwdh Wala'tmad Walttwyr Almdrsy, Edart Aljwdh Wala'tmad, Wzart Altrbyh Walt'lym Alymnyh, (2014).

[5] Al'etyby. Nasr S'd, Ttbyq Ala'tmad Almdrsy Fy Dw' Ass Edart Altghyyr Fy Mdars Alt'lym Al'am Bmdynt Alryad, (Atrwht Dktwrah Ghyr Mnshwrh), Jam't Am Alqra, Als'wdyh, (2016)

[6] 'lymat. Salh, Edart Aljwdh Alshamlh Fy Alm'ssat Altrbwyh, (Alttbyq Wmqtrhat Alttwyr), T1, 'man, Alardn, Dar Alshrwq Llnshr Waltwzy', (2012)

[7] Al'mayrh. Mhmd Hsn, Altrbyh Walt'lym Fy Alardn (Mnd Awakhr Al'ehd Al'thmany Whta 1997) (T1). 'man : Almysrh, (2000)

[8] Al'mry. Sbya', Ala'tmad Almdrsy, http://makkahnewspaper.com/ Tm Astrja'h Btarykh 11/1/2018

[9] Al'zam. Zkrya, M'eayyr Ala'tmad Al'am Walkhas Wdwrha Fy Rf' Jwdt Alt'lym Al'aly- Halh Drasyh Jam't Alzrqa' Alahlyh, Mjlt 'lwm Ensanyh. 4(31) (2007) ,1-33

[10] Accreditation International, http://www.aiaccredits.org/Home.html 
[11] Accreditation Standards for Dietetic Education Programs in Canada (2014), https://www.dietitians.ca/

[12] Ahmd. Ebrahym Ahmd, Aljwdh Alshamlh Fy Aledarh Alt'lymyh Walmdrsy, Aleskndryh, Dar Alwfa' Lltba'h Walnshr, (2003).

[13] Ahmd. Ebrahym, Ttbyqat Aljwdh Wala'tmad Fy Almdars, Alqahrh, Dar Alfkr Al'rby Llnshr Waltwzy', (2007).

[14] Alamyr. Mhmd, \& Al'wamlh. 'bdallh, Drjt Ttbyq M'ayyr Dman Aljwdh Fy Almdrsh Alardnyh Mn Wjht Nzr Almshrfyn Altrbwyyn, Almjlh Alardnyh Fy Al'lwm Altrbwyh, 7(1) (2011), 59-76.

[15] Alansary. 'ysa, Drash Mshyh Llkshf 'n Asbab Elhaq Alabna' Balmdars Alahlyh Wara' Alaba' Hwl Hdt Almdars. Alehsa', Als'wdyh, (2004).

[16] Ass A'tmad Wtrkhys Albramj Alt'lymyh Almkhtlfh Walthwyl Bynha Alsadrh Balastnad Llmadh (31/A) Mn Qanwn Altrbyh Walt'lym Rqm (3) Lsnh (1994).

[17] Alastl. 'ysa, Drjt Mmarst Mdyry Almdars Alkhash Fy Mhafzat Ghza Ledart Aljwdh Alshamlh W'laqtha Balmyzh Altnafsyh Llmdrsh, (Atrwht Aldktwrah Ghyr Mnshwrh), Aljam'h Aleslamyh, Ghza, (2013).

[18] Barresi. j., Standards for Accreditation of Oklahoma Schools 2014-2015 (2017), http://www.sde.ok.gov

[19] Aldham. Mhmd 'bd Alkrym, Ala'tmad Alakadymy Fy M'ssat Alt'lym Al'aly Wttbyqath Fy Aljam'at Al'rbyh Dlyl Altqwym Wala'tmad Alt'lymy Ma Qbl Alt'lym Aljam'y Almsry, (2009). Naqaae.Eg/Wp-Content/Uploads

[20] Aldwykat. Sna', Mrahl Alt'lym Fy Alardn, (2015), http://mawdoo3.com/ Tm Astrja'eha Btarykh 22/3/2018

[21] Dyab. Fatmh, Alhaj. Mysr, \& Kyaly. Majdh, Almdrsh Whdt Ttwyr Trbwy, Alm'tmr Alawl Lwkalh Alghwth Almn'qdh Fy 'man, Mn 24-27/4/2006.

[22] Ebrahym. Ahmd, Waq' Ala'tmad Altrbwy Almdrsy, Mjlt Nbha, 3(4) (2011), 307-311.

[23] Fairman. J., Peirce. B., \& Harris. W., High School Accreditation in Maine: Perceptions of Costs and Benefits, Center for Research and Evaluation, College of Education and Human Development, University of Maine, (2009).

[24] Gandal. M \& Vranek. J., sept. Standards: Here today, here tomorrow. Educational Leadership, 59 (1) (2001), 6-13.

[25] Alghamdy. 'ly, Drjt Ttbyq M'ayyr Dman Aljwdh Fy Almdars Als'wdyh Mn Wjht Nzr Almshrfyn Altrbwyyn Fy Almdynh Almnwrh, Almjlh Drasat Alardnyh Lldrasat Altrbwyh, 41(2) (2014), 947-995.

[26] Harvey. L \& Stensaker. B., Quality culture: understandings, boundaries and linkages, European Journal of Education, 43(4) (2008), 427- 442, https://doi.org/10.1111/j.1465-3435.2008.00367.x

[27] Hmwd. Kazm, Edart Aljwdh Alshamlh, Alardn, Dar Almsyrh Llnshr Waltwzy', (2002).

[28] Johansen. C., Jan. Total Quality management in a knowledge. management Journal of Documentation, 56 (1) (2010). 42-54 ,ERIC. E1608496.

[29] Joshua. C., Diversity and Social Justice in Teacher Education Accreditation Standards: 1995 to 2013. Submitted to the Graduate Faculty as partial fulfillment of the requirements for the Doctor of Philosophy Degree in Educational Sociology, (2015).

[30] Alk'by. N'ymh, Mstwa Thqyq M'ayyr Almhtwa Alakadymy 'nd Alatfal Altmhydy Fy Ryad Alatfal Fy Almmlkh Albhryn, (Atrwht Dktwrah Ghyr Mnshwrh), Aljam'h Alardnyh, (2004)

[31] Abw Khdyjh. Mhmd, Aljlsh Alsadsh. Dwr Alt'lym Alkhas Fy Al'mlyh Altrbwyh, Shyfh Alray, (2015) http://alrai.com/articltm astrja'eha btarykh 12/1/2018

[32] Khlyl. Nbyl, Almyzh Altnafsyh Fy Mjal Ala'mal, Aleskndryh, Aldar Aljam'yh Llnshr Waltwzy', (1998)

[33] Kh Rdy. Kawan Esma'yl, 'qd Alt'lym Alkhas, Drash Mqarnh, 'man: Dar Djlh, (2010)

[34] Alkhtyb. Ahmd, \& Alkhtyb. Rdah, Edart Aljwdh Alshamlh: Ttbyqat Trbwyh, Alardn, Dar Alktab Alhdyth, (2006).

[35] Alkhtyb. Smyr, Edart Aljwdh Alshamlh Walayzw, Mdkhl M'asr. Al'raq, Dar Almrtda Llnshr Waltwzy', (2008)

[36] Alkhtyb. Mhmd, Aljwdh Alshamlh Wala'tmad Alakadymy Fy Alt'lym,T1, Alryad, Dar Alkhryjy Llnshr Waltwzy', (2004) 
[37] Leithwood. K., Harris. A., \& Strauss. T., Leading school turnaround: How successful leaders transform lowperforming schools. San Francisco: Jossey-Bass, (2010).

[38] Almalky. Hmdh Bnt Mhmd, Ttbyq M'ayyr Ala'tmad Alakadymy Fy Mdars Alt'lym Althanwy Al'am Mn Wjht Nzr Alqyadat Altrbwyh Bmhafzh Jdh, (Rsalt Majstyr Ghyr Mnshwrh), Klyt Altrbyh, Jam't Am Alqra, (2010)

[39] McBrien. L., \& Brandt. R., The language of learning: A guide to education terms. Alexandria, VA: Association for Supervision and Curriculum Development, (1997).

[40] Mensching. B., School Accreditation and Its Impact on Our Wels Schools. (Unpublished Master Thesis) Martin Luther Collage. Denmark, (2012).

[41] Merhundrew. B., Superintendent Perceptions of the Accreditation Process in the State of Mississippi. Pro Quest LLC. 789 East Eisenhower Parkway, PO Box 1346, Ann Arbor, MI 48106, (2010).

[42] Moses. N. David. W. \& Stephen. 0., Total Quality Management in Secondary Schools in Kenya: Extent of Practice, Quality Assurance in Education. 14(4) (2006), 339- 362, https://doi.org/10.1108/09684880610703947

[43] National Council for Teacher Quality. (2014, September 1). About. Retrieved from .http://www.nctq.org/about/

[44] New Zealand Certificates for secondary schools » NZQA(2015), www.nzqa.govt.nz

[45] Pillsbury. SE., National Standards \& Quality Indicators Transition Toolkit forSystems Improvement, National Center on Secondary Education andTransition Institute on Community Integration (UCE), University of Minnesota, (2012).

[46] Qasm. Amjd, Nzm Ala'tmad Alakadymy, T'ryfh Wahmyth Wanwa'h(2012), Tm Astrja'h Mn Almrj' Btarykh 22/12/2017 http://al3loom.com/

[47] Alrfa'y. Ahmd, Nshr Thqaft Aljwdh Wala'tmad Fy Almdars Al'am, Bhth Mqdm Ela Allqa' Alsnwy (16), Lljm'yh Als'wdyh Ll'lwm Altrbwyh, Jam't Almlk Al S'wd, Alryad, (4-6) Fbrayr, 2013.

[48] Alrshdan. 'bd Allh, \& Hmshry, 'mr Ahmd, Nzam Altrbyh Walt'lym Fy Alardn, 'man: Mktbh Wa'l, (2002).

[49] Rshdy. T'ymh, Aljwdh Alshamlh Fy Alt'lym Byn M'shrat Altmyz Wm'ayyr Ala'tmad (Alass Walttbyqat)) ,T1 Alardn, Dar Almsyrh Llnshr Waltwzy', (2006).

[50] Alrys. Nasr, Khtt Astratyjyh Mstqblyh Lla'tmad Almdrsy(Ahmyt, Asbab, Walm'yqat), Bhth Mqdm Ela Allqa' Alsnwy (16) Lljm'yh Als'wdyh Ll'lwm Altrbwyh Walnfsyh(Jstn), Jam't Almlk Al S'wd, Alryad, (4-6) Fbrayr, 2013.

[51] Abw Rzq. Hlymh 'ly, Almdkhl Ela Altrbyh, (T1), 'man: Dar Aljyl, (1998).

[52] Alshaf'y. Ahmd \& Alsyd. Mhmd, Thqaft Aljwdh Fy Alfkr Aledary Altrbwy Alyabany, Wemkanyh Alastfadh Mnh Fy Msr, Mjlt Alabhath Alyrmwk, Alardn, Al'dd(4) (2003).

[53] Alshamsy. Shykhh, Dlyl Tqyym Almdars (2010-2011), Services.Moe.Gov.Ae Almstrj' Btarykh 2/2/2018

[54] Shdyfat. Amyn, Alt'elym Alkhas Shryk Asasy Fy Mkhrjat Alqta'e, Tm Astrja'h 12/2/2018 http://www.sarayanews.com/

[55] Alshrqawy. Mrym, Edart Almdars Baljwdh Alshamlh, T2, Msr, Mktbt Alnhdh Almsryh Llnshr Waltwzy', (2002)

[56] Special Education (2017), www.edb.gov.hk/en/edu-system/special/policy

[57] Wiggins. G., Standards, Not Standardization: Evoking Quality Student Work . Educational Leadership, 48(5) (1995).

[58] Williams. G. O., Identifying Principals'Practices That Affect Achievement And Accreditation Of Public Elementary, Middle, And High Schools In Virginia (Doctoral dissertation, Virginia Polytechnic Institute and State University, (2008).

[59] Alzwawy. Khald, Aljwdh Alshamlh Fy Alt'lym, Mjmw't Alnyl Al'rbyh Alqahrh, Jmhwryt Msr Al'rbyh, (2003). 